\title{
Influence of viscosity and compressibility of aerated oil on determination of volumetric losses in a variable capacity piston pump
}

Jan Koralewski, M. Sc.,

Gdansk University of Technology, Poland

\begin{abstract}
Modulus $B$ of the liquid volume elasticity of non-aerated and aerated oil is defined in the paper as relation to the indicated increase of pressure in the pump working chambers, with the change of oil temperature and degree of aeration. In evaluation of the losses due to oil compressibility in a variable capacity displacement pump, the volume of compressed liquid at each pump setting is taken into account. Volumetric losses have been divided into leakage losses in the pump chambers and losses due to liquid compressibility. The need of accounting for only the leakage losses for pump evaluation is pointed out.
\end{abstract}

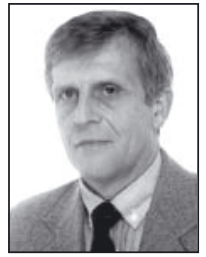

Keywords: hydrostatic drive, variable capacity displacement pump, liquid aeration, method of determining the degree of liquid aeration

\section{INTRODUCTION}

In references [1-3] the Author presented results of investigations of the influence of hydraulic oil viscosity on volumetric losses in a variable capacity piston pump. The tests were carried out with a HYDROMATIK A7V.58.1.R.P.F.00 type pump of bent axis design, without taking into account the hydraulic oil compressibility. The investigations were performed on a test stand in the Hydraulic and Pneumatics Laboratory of the Faculty of Mechanical Engineering and the results were elaborated in the Chair of Marine Mechatronics of the Faculty of Ocean Engineering and Ship Technology of the Gdansk University of Technology.

The tests were performed with:

- 8 hydraulic oil temperatures $\vartheta$ (oil kinematic viscosity $v$ ): $\vartheta=20^{\circ} \mathrm{C}\left(v=120.40 \mathrm{~mm}^{2} \mathrm{~s}^{-1}\right), \vartheta=24^{\circ} \mathrm{C}\left(v=91.16 \mathrm{~mm}^{2} \mathrm{~s}^{-1}\right)$, $\vartheta=30^{\circ} \mathrm{C}\left(v=65.37 \mathrm{~mm}^{2} \mathrm{~s}^{-1}\right), \vartheta=36^{\circ} \mathrm{C}\left(v=47.05 \mathrm{~mm}^{2} \mathrm{~s}^{-1}\right)$, $\vartheta=43^{\circ} \mathrm{C}\left(v=34.68 \mathrm{~mm}^{2} \mathrm{~s}^{-1}\right), \vartheta=50^{\circ} \mathrm{C}\left(v=26.41 \mathrm{~mm}^{2} \mathrm{~s}^{-1}\right)$, $\vartheta=60^{\circ} \mathrm{C}\left(v=18.77 \mathrm{~mm}^{2} \mathrm{~s}^{-1}\right), \vartheta=68^{\circ} \mathrm{C}\left(v=14.53 \mathrm{~mm}^{2} \mathrm{~s}^{-1}\right)$,

- 8 values of increase $\Delta \mathrm{p}_{\mathrm{p}}$ pressure in the pump:

$\Delta \mathrm{p}_{\mathrm{P}}=1.6 \mathrm{MPa}, \Delta \mathrm{p}_{\mathrm{P}}=3.2 \mathrm{MPa}, \Delta \mathrm{p}_{\mathrm{P}}=6.3 \mathrm{MPa}$,

$\Delta \mathrm{p}_{\mathrm{P}}=10 \mathrm{MPa}, \Delta \mathrm{p}_{\mathrm{P}}=16 \mathrm{MPa}, \Delta \mathrm{p}_{\mathrm{P}}=20 \mathrm{MPa}$,

$\Delta \mathrm{p}_{\mathrm{P}}=25 \mathrm{MPa}, \Delta \mathrm{p}_{\mathrm{P}}=32 \mathrm{MPa}$,

- 7 values of pump capacity coefficient $b_{\mathrm{P}}$ :

$b_{\mathrm{P}}=0.225 ; b_{\mathrm{P}}=0.361 ; b_{\mathrm{P}}=0.493$;

$\mathrm{b}_{\mathrm{P}}=0.623 ; \mathrm{b}_{\mathrm{P}}=0.752 ; \mathrm{b}_{\mathrm{P}}=0.880 ; \mathrm{b}_{\mathrm{P}}=1$.

The Author presents in this paper results of the investigations of the effect of viscosity and compressibility of non-aerated and aerated oil on determination of volumetric losses in a variable capacity piston pump.
The problem of effect of compressibility of the non-aerated and aerated working liquid on volumetric and mechanical losses in a variable capacity displacement pump has been undertaken by Zygmunt Paszota [4-10].

In reference [13] Z. Paszota presented his method of determining the degree of aeration of liquid flowing in a variable capacity displacement pump.

The Author is the first user of the method in his research work into the influence of liquid aeration and viscosity on mechanical and volumetric losses in the pump.

\section{LIQUID COMPRESSIBILITY IN A VARIABLE CAPACITY PISTON PUMP}

The term „compressibility” defines susceptibility of liquid to volumetric strain with changing pressure. The measure of strain is compressibility coefficient $\beta$ defined as:

$$
\beta=-\frac{1}{V_{0}} \frac{d V}{d p}
$$

For finite increments, relations may be used of change of initial volume $\mathrm{V}_{0}$ with increase of pressure by a value $\Delta \mathrm{p}$ :

$$
\Delta \mathrm{V}=-\beta \mathrm{V}_{0} \Delta \mathrm{p}
$$

The inverse of compressibility coefficient is modulus B of the liquid volume elasticity:

$$
\mathrm{B}=1 / \beta
$$

For mineral oils, modulus B depends on pressure $\mathrm{p}$ and temperature $\vartheta$. These relations are illustrated in diagrams (Fig. 1 and Fig. 2). 


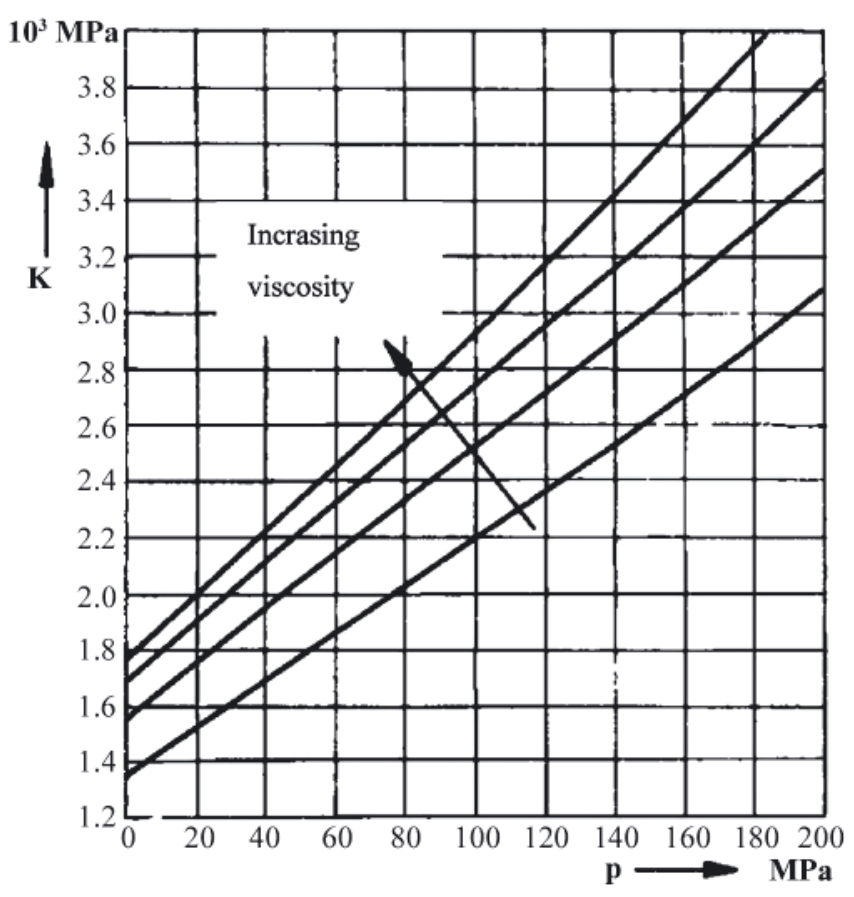

Fig. 1. Relation of modulus $K$ of volumetric strain $K$ of mineral oils to pressure and viscosity [12]

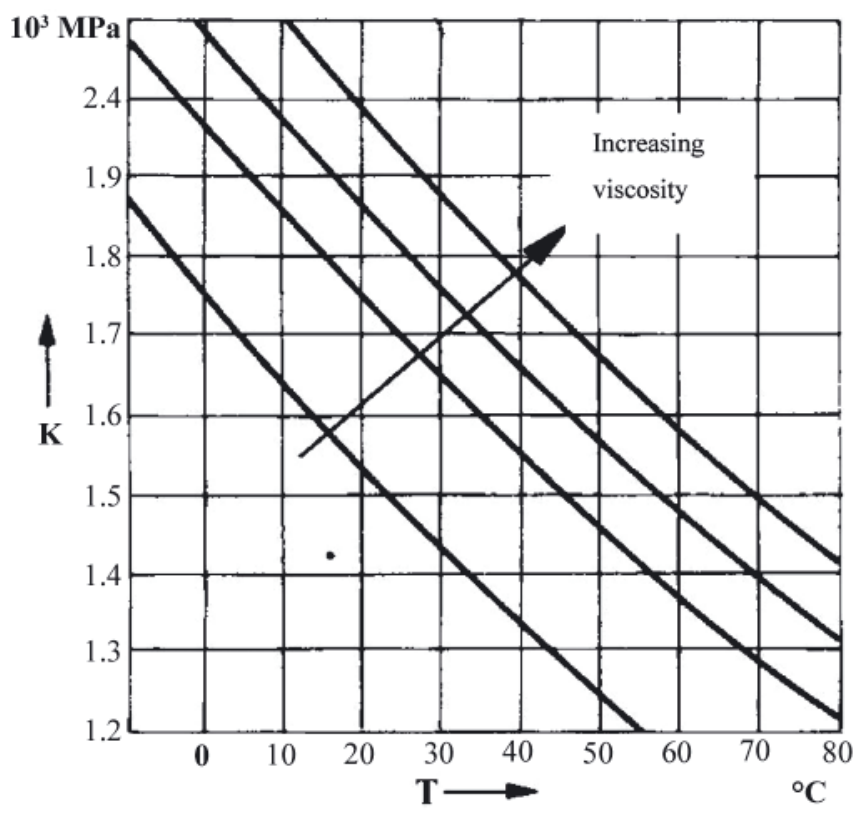

Fig. 2. Relation of modulus $K$ of volumetric strain of mineral oils to temperature and viscosity [12]

Numerical values of modulus B of the used hydraulic oils are the following [11]:

- at the normal temperature $\left(20^{\circ} \mathrm{C}\right)$, close to $\mathrm{B}=1500 \mathrm{MPa}$,

- $\mathrm{B}$ increases with the pressure (by about $1 \%$ every $2 \mathrm{MPa}$ up to $\left.20 \mathrm{MPa}\left(\mathrm{a}_{\mathrm{p}}=0.005 / 1 \mathrm{MPa}\right)\right)$,

- B decreases when the temperature increases (about 1\% every $2^{\circ} \mathrm{C}$ up to $\left.100^{\circ} \mathrm{C}\left(\mathrm{a}_{\vartheta}=-0.005 / 1^{\circ} \mathrm{C}\right)\right)$.

In working chambers of the tested piston pump during their connection with the inlet channel was slight overpressure $\mathrm{p}_{\mathrm{Pli}} \approx 0.05 \mathrm{MPa}$ (i.e. absolute pressure $\mathrm{p}_{\mathrm{Pli}} \approx 0.15 \mathrm{MPa}$ ). Let's assume that the value of modulus $\mathrm{B}$ of the hydraulic oil volume elasticity, at the temperature $\vartheta=20^{\circ} \mathrm{C}$, equals to:

$$
\mathrm{B}_{\mid \mathrm{p}_{\mathrm{Plia}} \approx 0.15 \mathrm{MPa} ; \vartheta=20^{\circ} \mathrm{C}}=1500 \mathrm{MPa}
$$

Therefore, the dependence of modulus B of oil on the increase $\Delta \mathrm{p}_{\mathrm{Pi}}$ of pressure in the working chambers and on the increase $\Delta \vartheta$ of oil temperature may be described by the expression:

$$
\mathrm{B}=\mathrm{B}_{\mid \mathrm{p}_{\mathrm{P} 1 \mathrm{ia}} \approx 0.15 \mathrm{MPa} ; \vartheta=20^{\circ} \mathrm{C}}\left(1+\mathrm{a}_{\mathrm{p}} \Delta \mathrm{p}_{\mathrm{Pi}}+\mathrm{a}_{\vartheta} \Delta \vartheta\right)
$$

The hydraulic oil compressibility depends to a great extent on the contents of non-dissolved air. The measure of nondissolved air in oil is the oil aeration coefficient $\varepsilon$-ratio of the volume $\mathrm{V}_{\mathrm{a}}$ of air to the volume $\mathrm{V}_{0}=\mathrm{V}_{\mathrm{o}}+\mathrm{V}_{\mathrm{a}}$ of mixture equal to the sum of oil volume $\mathrm{V}_{\mathrm{o}}$ and air volume $\mathrm{V}_{\mathrm{a}}$ :

$$
\varepsilon=\frac{\mathrm{V}_{\mathrm{a}}}{\mathrm{V}_{\mathrm{o}}+\mathrm{V}_{\mathrm{a}}}=\frac{\mathrm{V}_{\mathrm{a}}}{\mathrm{V}_{0}}
$$

The oil aeration coefficient $\varepsilon$ is determined at the absolute pressure $\mathrm{p}_{\mathrm{Plia}}$ in the pump working chambers during their connection with the inlet channel.

An increase $\Delta \mathrm{p}_{\mathrm{Pi}}$ of pressure in the pump working chambers causes a decrease of the oil and air mixture volume by the value $\Delta \mathrm{V}$ (assuming a hypothesis of compression of air $\mathrm{pV}$ $=$ cte) equal to:

$$
\Delta \mathrm{V}=\Delta \mathrm{V}_{\mathrm{o}}+\Delta \mathrm{V}_{\mathrm{a}}=\frac{\mathrm{V}_{\mathrm{o}}}{\mathrm{B}} \Delta \mathrm{p}_{\mathrm{Pi}}+\frac{\mathrm{V}_{\mathrm{a}}}{\mathrm{p}_{\mathrm{P} \text { lia }}+\Delta \mathrm{p}_{\mathrm{Pi}}} \Delta \mathrm{p}_{\mathrm{Pi}}
$$

If the aeration coefficient $\varepsilon$ is small, which is a general case, $\mathrm{V}_{\mathrm{o}}$ is close to $\mathrm{V}_{0}$. Therefore, it can, be written [11]:

$$
\Delta \mathrm{V}=\mathrm{V}_{0}\left(\frac{1}{\mathrm{~B}}+\frac{\varepsilon}{\mathrm{p}_{\mathrm{P} 1 \mathrm{ia}}+\Delta \mathrm{p}_{\mathrm{Pi}}}\right) \Delta \mathrm{p}_{\mathrm{Pi}}
$$

Modulus B' of aerated hydraulic oil volume elasticity is defined by the expression:

$$
\frac{1}{\mathrm{~B}^{\prime}}=\frac{1}{\mathrm{~B}}+\frac{\varepsilon}{\mathrm{p}_{\mathrm{P} 1 \mathrm{ia}}+\Delta \mathrm{p}_{\mathrm{Pi}}}
$$

or, in the conditions of changing the aerated oil pressure and temperature, by the expression:

$$
\begin{gathered}
\frac{1}{\mathrm{~B}^{\prime}}=\frac{1}{\mathrm{~B}_{\mid \mathrm{p}_{\mathrm{Pli}} \approx 0.15 \mathrm{MPa}, \vartheta=20^{\circ} \mathrm{C}}\left(1+\mathrm{a}_{\mathrm{p}} \Delta \mathrm{p}_{\mathrm{Pi}}+\mathrm{a}_{\vartheta} \Delta \vartheta\right)} \\
+\frac{\varepsilon}{\mathrm{p}_{\mathrm{P} 1 \mathrm{ia}}+\Delta \mathrm{p}_{\mathrm{Pi}}}
\end{gathered}
$$

Fig. 3 presents modulus B of non-aerated $(\varepsilon=0)$ oil volume elasticity and modulus B' of aerated $(\varepsilon>0)$ oil volume elasticity as dependent on the indicated increase $\Delta \mathrm{p}_{\mathrm{Pi}}$ of pressure in the pump working chambers with the hydraulic oil temperature limit values $\vartheta=20^{\circ} \mathrm{C}$ and $\vartheta=68^{\circ} \mathrm{C}$ assumed during the tests.

In a variable capacity pump, the initial oil volume $\mathrm{V}_{0}$ (Fig. 4), subjected to compression in effect of increase $\Delta p_{\mathrm{Pi}}$ of pressure in the chambers, corresponding to setting $\mathrm{q}_{\mathrm{Pgv}}$ of variable geometrical working capacity, is equal to:

$$
\mathrm{V}_{0}=0.5 \mathrm{q}_{\mathrm{Pt}}+0.5 \mathrm{q}_{\mathrm{Pgv}}
$$

When the variable (set) geometrical working capacity $\mathrm{q}_{\mathrm{Pgv}}$ reaches the maximum value equal to the pump theoretical working capacity $\mathrm{q}_{\mathrm{Pt}}\left(\mathrm{q}_{\mathrm{Pgv}}=\mathrm{q}_{\mathrm{Pt}}\right)$, the compressed oil volume $\mathrm{V}_{0}$ has the value:

$$
\mathrm{V}_{0}=0.5 \mathrm{q}_{\mathrm{Pt}}+0.5 \mathrm{q}_{\mathrm{Pt}}=\mathrm{q}_{\mathrm{Pt}}
$$

The change $\Delta \mathrm{V}$ of liquid volume due to compression of liquid as an effect of increase $\Delta \mathrm{p}_{\mathrm{Pi}}$ of pressure in the pump chambers (presented in Fig. 4) equals to the volumetric losses $\mathrm{q}_{\mathrm{Pvc}}$ due to compression of oil during one pump shaft revolution: 


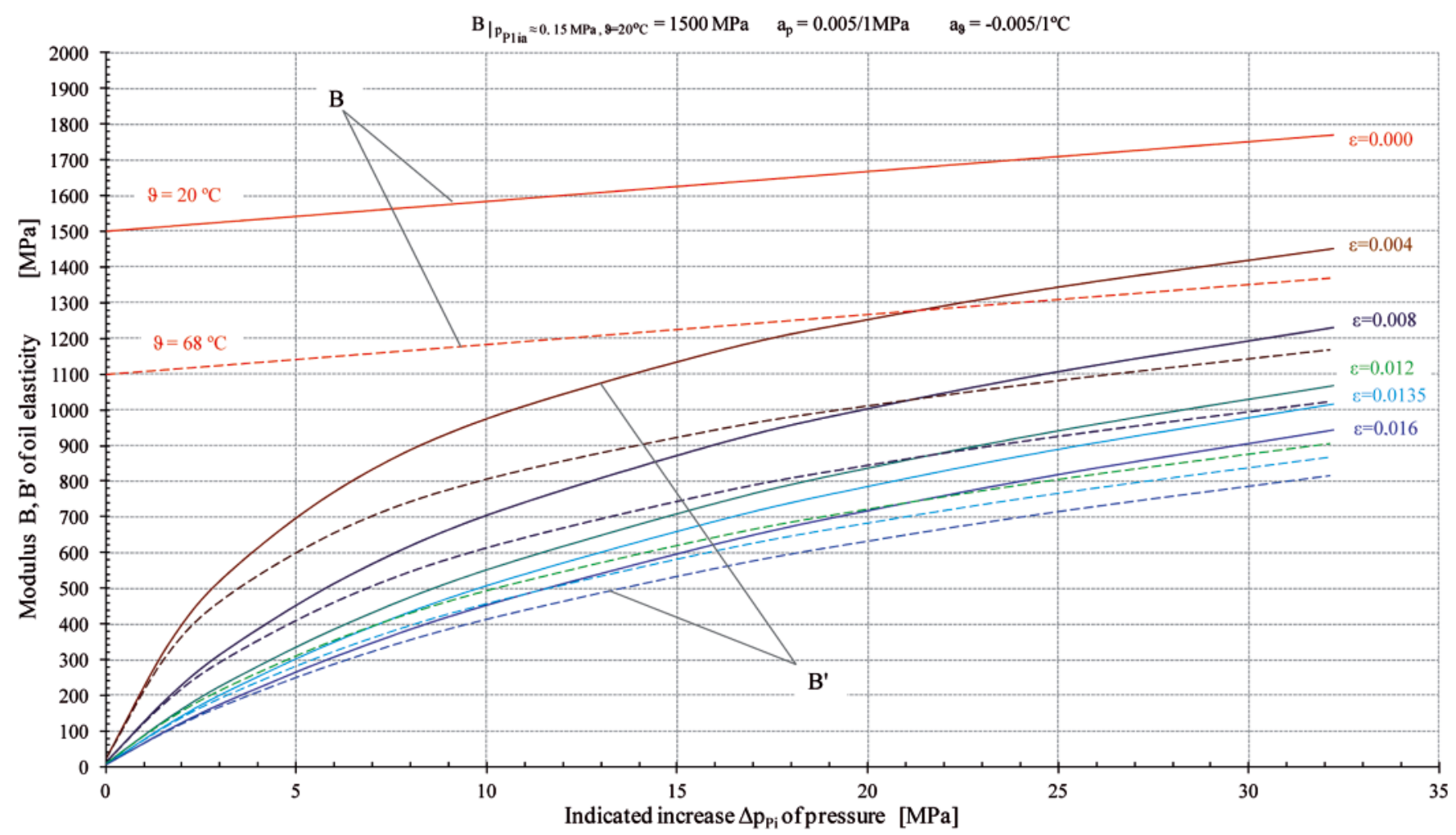

Fig. 3. Modulus B of volume elasticity of non-aerated hydraulic oil $(\varepsilon=0)$ and modulus B' of aerated oil ( $\varepsilon>0)$ as relations dependent on indicated increase $\Delta p_{P i}$ of pressure in the pump working chambers, with limit values $\vartheta=20^{\circ} \mathrm{C}$ (continuous line) and $\vartheta=68^{\circ} \mathrm{C}$ (dashed line) of hydraulic oil temperature adopted during the investigations. It was assumed that modulus $B$ of oil volume elasticity at absolute pressure $p_{\text {Plia }} \approx 0.15$ MPa in the pump working chambers during their connection with the inlet channel and at oil temperature $\vartheta=20^{\circ} \mathrm{C}$ is equal to $B=1500 \mathrm{MPa}$. Also assumed was the value of coefficient $a_{p}=0.005 / 1 \mathrm{MPa}$ of the change of modulus $B$ of oil due to increase $\Delta p_{P_{i}}$ of pressure in the working channels and coefficient $a_{\vartheta}=-0.005 / 1{ }^{\circ} \mathrm{C}$ of the change of modulus $B$ due to change of oil temperature $\vartheta$

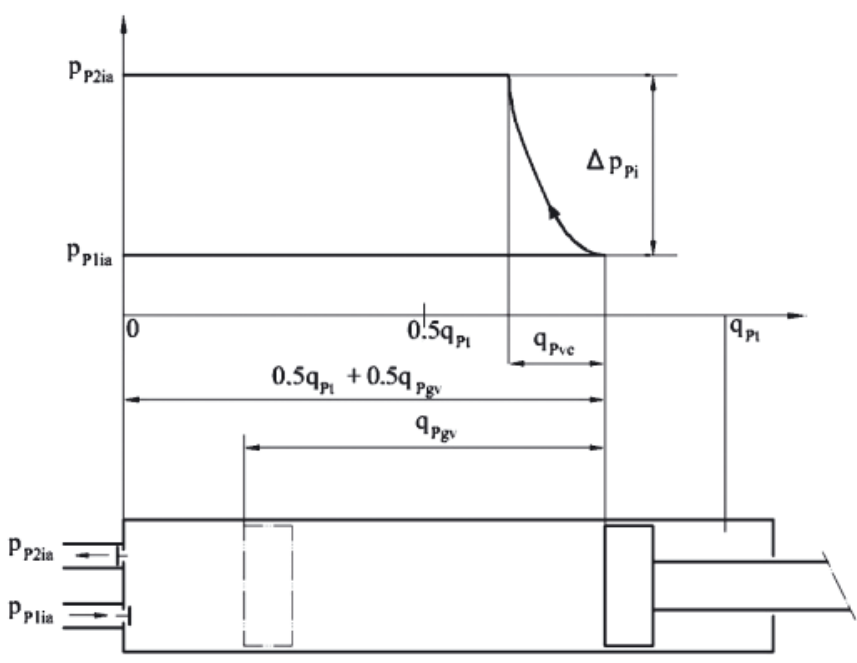

Fig. 4. Initial oil volume $\left(0.5 q_{P t}+0.5 q_{P g v}\right)$ subjected to compression in a variable capacity displacement pump in effect of increase $\Delta p_{P_{i}}$ of pressure in the chambers, corresponding to setting $q_{P g v}$ of variable geometrical working capacity

$$
\Delta \mathrm{V}=\mathrm{q}_{\mathrm{Pvc}}
$$

The losses $\mathrm{q}_{\mathrm{Pvc}}$ of pump capacity per one shaft revolution (Fig. 4) due to compressibility of non-aerated (or aerated) oil, occurring with setting $\mathrm{q}_{\mathrm{pgv}}$ of variable geometrical capacity, is determined (in reference to (7) and (8)) by the formula:

$$
\mathrm{q}_{\mathrm{Pvc}}=\frac{\left(0.5 \mathrm{q}_{\mathrm{Pt}}+0.5 \mathrm{q}_{\mathrm{Pt}}\right) \Delta \mathrm{p}_{\mathrm{Pi}}}{\mathrm{B}^{\prime}}
$$

and with $\mathrm{q}_{\mathrm{Pgv}}=\mathrm{q}_{\mathrm{Pt}}$ by the formula:

$$
\mathrm{q}_{\mathrm{Pvc}}=\frac{\mathrm{q}_{\mathrm{Pt}} \Delta \mathrm{p}_{\mathrm{Pi}}}{\mathrm{B}^{\prime}}
$$

after replacing 1/B' by expression (10), by the formula:

$$
\left.\begin{array}{c}
\mathrm{q}_{\mathrm{Pvc}}=\left(0.5 \mathrm{q}_{\mathrm{Pt}}+0.5 \mathrm{q}_{\mathrm{Pgv}}\right) . \\
\cdot\left[\frac{1}{\mathrm{~B}_{\mid \mathrm{p}_{\mathrm{Plia}} \approx 0.15 \mathrm{MPa}, \vartheta=20^{\circ \mathrm{C}}}\left(1+\mathrm{a}_{\mathrm{p}} \Delta \mathrm{p}_{\mathrm{Pi}}+\mathrm{a}_{\vartheta} \Delta \vartheta\right)}+\frac{\varepsilon}{\mathrm{p}_{\mathrm{Plia}}+\Delta \mathrm{p}_{\mathrm{Pi}}}\right.
\end{array}\right] \Delta \mathrm{p}_{\mathrm{Pi}}
$$

and, with $\mathrm{q}_{\mathrm{Pg}}=\mathrm{q}_{\mathrm{Pt}}$, by the formula:

$$
=\mathrm{q}_{\mathrm{Pt}} \cdot\left[\begin{array}{c}
\mathrm{q}_{\mathrm{Pvc}}= \\
\frac{1}{\mathrm{~B}_{\mid \mathrm{p}_{\mathrm{Pli}} \approx 0.15 \mathrm{MPa}, \vartheta=20^{\circ} \mathrm{C}}\left(1+\mathrm{a}_{\mathrm{p}} \Delta \mathrm{p}_{\mathrm{Pi}}+\mathrm{a}_{\vartheta} \Delta \vartheta\right)}+\mathrm{p}_{\mathrm{Pi}} \\
+\frac{\varepsilon}{\mathrm{p}_{\mathrm{Plia}}+\Delta \mathrm{p}_{\mathrm{Pi}}}
\end{array}\right] \Delta
$$

Fig. 5 presents an example (with assumed oil aeration coefficient $\varepsilon=0.0135$ ) of calculations of the losses $\mathrm{q}_{\mathrm{Pvc}}=\mathrm{f}\left(\Delta \mathrm{p}_{\mathrm{Pi}}\right)$ of pump capacity per one pump shaft revolution, taking into account formula (16) for cases of variable geometrical working capacity settings $\mathrm{q}_{\mathrm{Pgv}}$ and formula (17) for the maximum setting $\mathrm{q}_{\mathrm{Pgv}}=\mathrm{q}_{\mathrm{Pt}}$, i.e. pump theoretical working capacity.

The change of losses $\mathrm{q}_{\mathrm{Pvc}}$ of pump capacity per one shaft revolution due to the liquid compressibility, as a relation to the indicated increase $\Delta \mathrm{p}_{\mathrm{pi}}$ of pressure in the working chambers, presented in Fig. 5, takes into account the influence of changing volumes $V_{0}$ (Fig. 4) of liquid in working chambers subjected to compression and being an effect of operation of 


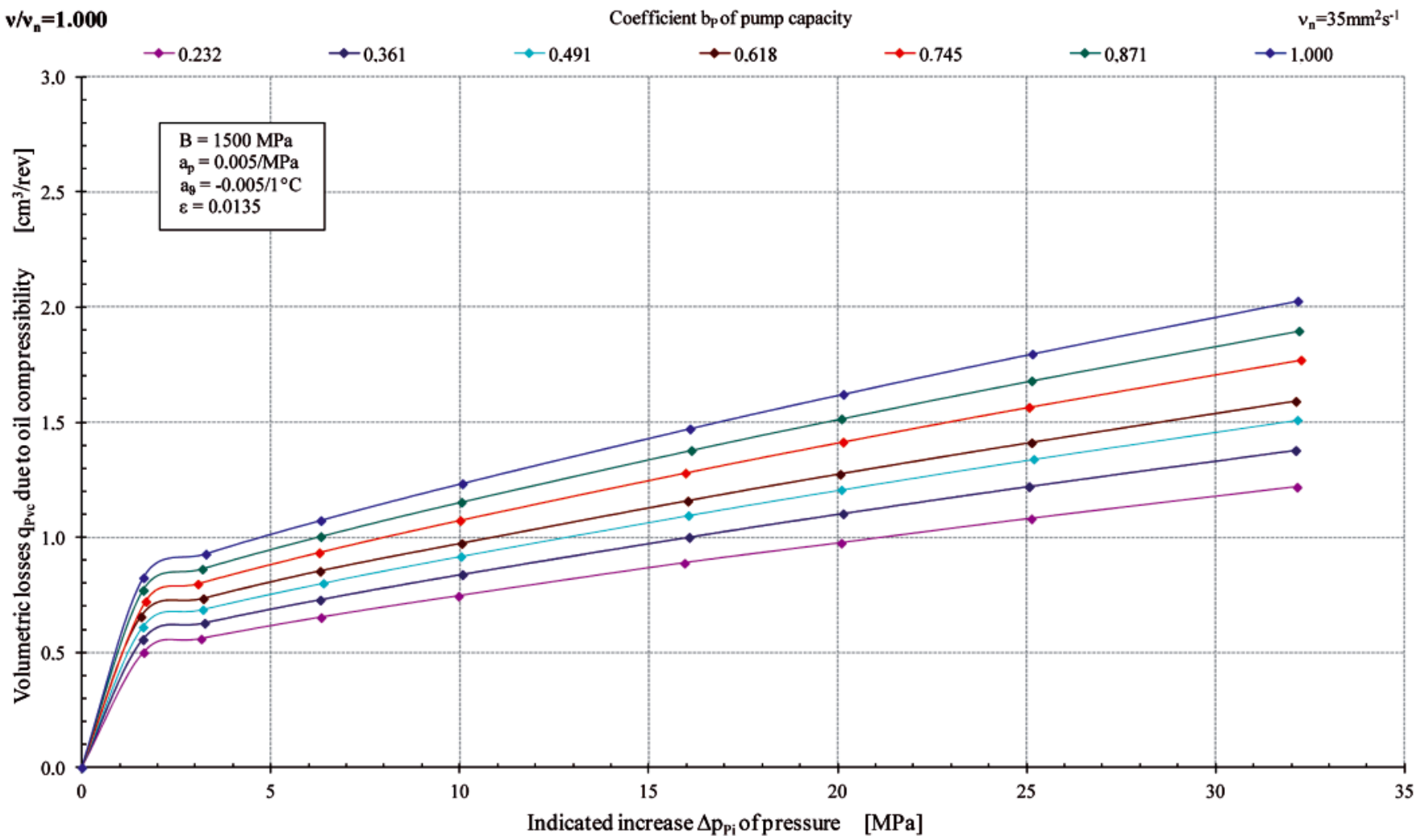

Fig. 5. Losses $q_{P v c}$ of pump capacity during one pump shaft revolution due to compressibility of aerated $(\varepsilon=0.0135)$ liquid, decreasing the active volume of liquid displaced by the pump compared with the theoretical working capacity $q_{P t}\left(b_{P}=1\right)$ or geometrical working capacity $q_{P g v}\left(0 \leq b_{P} \leq 1\right)$ (pump of HYDROMATIK A7V.DR.1.R.P.F.00 type)

a variable capacity $\mathrm{q}_{\mathrm{Pgv}}$ (variable $\mathrm{b}_{\mathrm{P}}$ coefficient) per one shaft revolution.

The losses $\mathrm{q}_{\mathrm{Pvc}}$ of pump capacity per one shaft revolution due to the liquid compressibility reduces the active volume of liquid displaced by the pump compared with the theoretical working capacity $\mathrm{q}_{\mathrm{Pt}}$ or geometrical variable working capacity $\mathrm{q}_{\mathrm{Pgv}}$ (determined at $\Delta \mathrm{p}_{\mathrm{Pi}}=0$ ). This fact must be taken into account in evaluation of intensity $\mathrm{q}_{\mathrm{Pv}}=\mathrm{Q}_{\mathrm{Pv}} / \mathrm{n}_{\mathrm{P}}$ of volumetric losses in working chambers and in evaluation of the increase $\Delta \mathrm{M}_{\mathrm{Pm}_{\mathrm{m}} \mid \Delta \mathrm{p}_{\mathrm{pi}}}$ of torque of mechanical losses in the „working chambers - shaft" assembly, the losses caused by the increase $\Delta \mathrm{p}_{\mathrm{Pi}}$ of pressure in the pump working chambers.

\section{DETERMINING THE PUMP \\ GEOMETRICAL VARIABLE WORKING CAPACITY $q_{\text {Pgv }}$ AND THEORETICAL WORKING CAPACITY $\mathbf{q}_{\mathrm{Pt}}$}

It is essential, particularly in evaluation of operating characteristics of a displacement pump with variable capacity per one shaft revolution, to determine precisely the pump theoretical working capacity $\mathrm{q}_{\mathrm{pt}}$ and geometrical working capacities $\mathrm{q}_{\mathrm{Pgv}}$. The geometrical working capacities $\mathrm{q}_{\mathrm{Pgv}}$ change in the $0 \leq \mathrm{q}_{\mathrm{Pgv}} \leq \mathrm{q}_{\mathrm{Pt}}$ range and the corresponding coefficients $\mathrm{b}_{\mathrm{P}}$ $=\mathrm{q}_{\mathrm{Pgv}} / \mathrm{q}_{\mathrm{Pt}}$ of pump capacity change in the $0 \leq \mathrm{b}_{\mathrm{P}} \leq 1$ range. The precise evaluation of $b_{P}=q_{P g v} / q_{P t}$ coefficient depends on the precise evaluation of $\mathrm{q}_{\mathrm{Pgv}}$ and $\mathrm{q}_{\mathrm{Pt}}$.

The pump theoretical working capacity $\mathrm{q}_{\mathrm{Pt}}$ and geometrical working capacities $\mathrm{q}_{\mathrm{Pgv}}$ are evaluated at the indicated increase $\Delta \mathrm{p}_{\mathrm{Pi}}$ of pressure in the working chambers equal zero $\left(\Delta \mathrm{p}_{\mathrm{Pi}_{\mathrm{i}}}=0\right)$. Their values are determined by approximation at $\Delta \mathrm{p}_{\mathrm{Pi}}=0$ point of the $\mathrm{q}_{\mathrm{P}}=\mathrm{Q}_{\mathrm{P}} / \mathrm{n}_{\mathrm{P}}=\mathrm{f}\left(\Delta \mathrm{p}_{\mathrm{Pi}}\right)$ line describing, with the fixed pump setting (but not known exactly value of $b_{p}$ coefficient), the value $\mathrm{q}_{\mathrm{P}}$ displaced in one shaft revolution as a relation to $\Delta \mathrm{p}_{\mathrm{P}}$. The line $\mathrm{q}_{\mathrm{P}}=\mathrm{f}\left(\Delta \mathrm{p}_{\mathrm{Pi}}\right)$ is determined by measurement points obtained from the tests.

Fig. 6 presents an example of the relation $\mathrm{q}_{\mathrm{p}}=\mathrm{f}\left(\Delta \mathrm{p}_{\mathrm{P}}\right)$ of capacity $\mathrm{q}_{\mathrm{p}}$ per one shaft revolution of the tested axial piston pump to the indicated increase $\Delta \mathrm{p}_{\mathrm{Pi}}$ of pressure in working chambers with coefficients $b_{P}=0.225$ and $b_{P}=1$ of pump capacity per one shaft revolution. Therefore, these examples present searching for geometrical working capacity $\mathrm{q}_{\mathrm{Pgv}}$ and theoretical working capacity $\mathrm{q}_{\mathrm{pt}}$ per one shaft revolution as well as evaluation of the subdivision of the intensity $\mathrm{q}_{\mathrm{Pv}_{\mathrm{v}}}$ of volumetric losses per one shaft revolution into the volumetric losses $\mathrm{q}_{\mathrm{Pvl}}$ due to oil leakage in working chambers and volumetric losses $\mathrm{q}_{\mathrm{Pvc}}$ due to compressibility of non-aerated (or aerated) oil.

The losses $\mathrm{q}_{\mathrm{Pvc}}=\mathrm{f}\left(\Delta \mathrm{p}_{\mathrm{Pi}}\right)$ per one shaft revolution determined by formula (16), resulting from the liquid compressibility, occurring with setting $\mathrm{q}_{\mathrm{Pgv}}$ of the pump variable geometrical working volume (or by formula (17) with setting $\mathrm{q}_{\mathrm{Pt}}$ of the pump theoretical working volume) are added to capacity $\mathrm{q}_{\mathrm{p}}=\mathrm{f}\left(\Delta \mathrm{p}_{\mathrm{Pi}}\right)$ per one shaft revolution determined by the line drawn through the measurement points. The result of adding $\mathrm{q}_{\mathrm{Pvc}}=\mathrm{f}\left(\Delta \mathrm{p}_{\mathrm{Pi}}\right)$ to $\mathrm{q}_{\mathrm{P}}=\mathrm{f}\left(\Delta \mathrm{p}_{\mathrm{Pi}}\right)$ is the line $\mathrm{q}_{\mathrm{P} \text { without compressibility }}=\mathrm{f}\left(\Delta \mathrm{p}_{\mathrm{P}_{\mathrm{i}}}\right)$ of pump capacity as a difference between $\mathrm{q}_{\mathrm{Pgv}}\left(\right.$ or $\mathrm{q}_{\mathrm{Pt}}$ ) and the volumetric losses $\mathrm{q}_{\mathrm{Pvl}}$ due to oil leakage (independent of the liquid compressibility):

$$
\left(\mathrm{q}_{\mathrm{P} \text { without compressibility }}=\mathrm{q}_{\mathrm{Pvc}}+\mathrm{q}_{\mathrm{P}}\right)=\mathrm{f}\left(\Delta \mathrm{p}_{\mathrm{Pi}}\right)
$$

$$
\left(\mathrm{q}_{\mathrm{P} \text { without compressibility }}=\mathrm{q}_{\mathrm{Pgv}}\left(\text { or } \mathrm{q}_{\mathrm{Pt}}\right)-\mathrm{q}_{\mathrm{Pvl}}\right)=\mathrm{f}\left(\Delta \mathrm{p}_{\mathrm{Pi}}\right)
$$

Approximation of the line $\mathrm{q}_{\mathrm{P} \text { without compressibility }}=\mathrm{f}\left(\Delta \mathrm{p}_{\mathrm{Pi}}\right)$ with $\Delta \mathrm{p}_{\mathrm{Pi}}=0$ allows to determine the value $\mathrm{q}_{\mathrm{Pgv}}\left(\right.$ or $\left.\mathrm{q}_{\mathrm{Pt}}\right)$ :

$$
\mathrm{q}_{\mathrm{P} \text { without compressibility } \mid \Delta \mathrm{p}_{\mathrm{Pi}}=0}=\mathrm{q}_{\mathrm{Pgv}}\left(\text { or } \mathrm{q}_{\mathrm{Pt}}\right)
$$




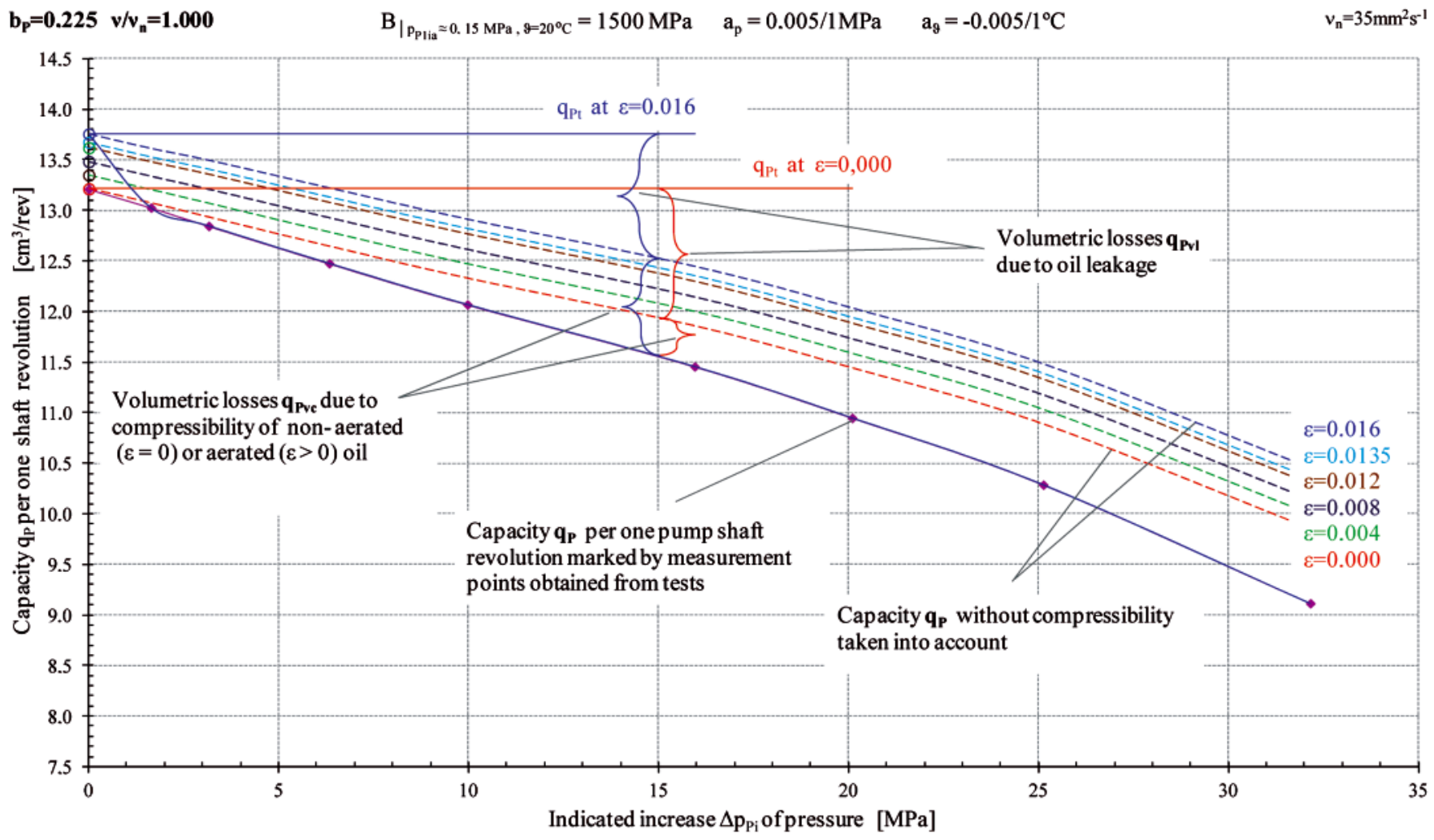

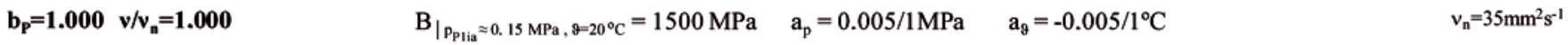

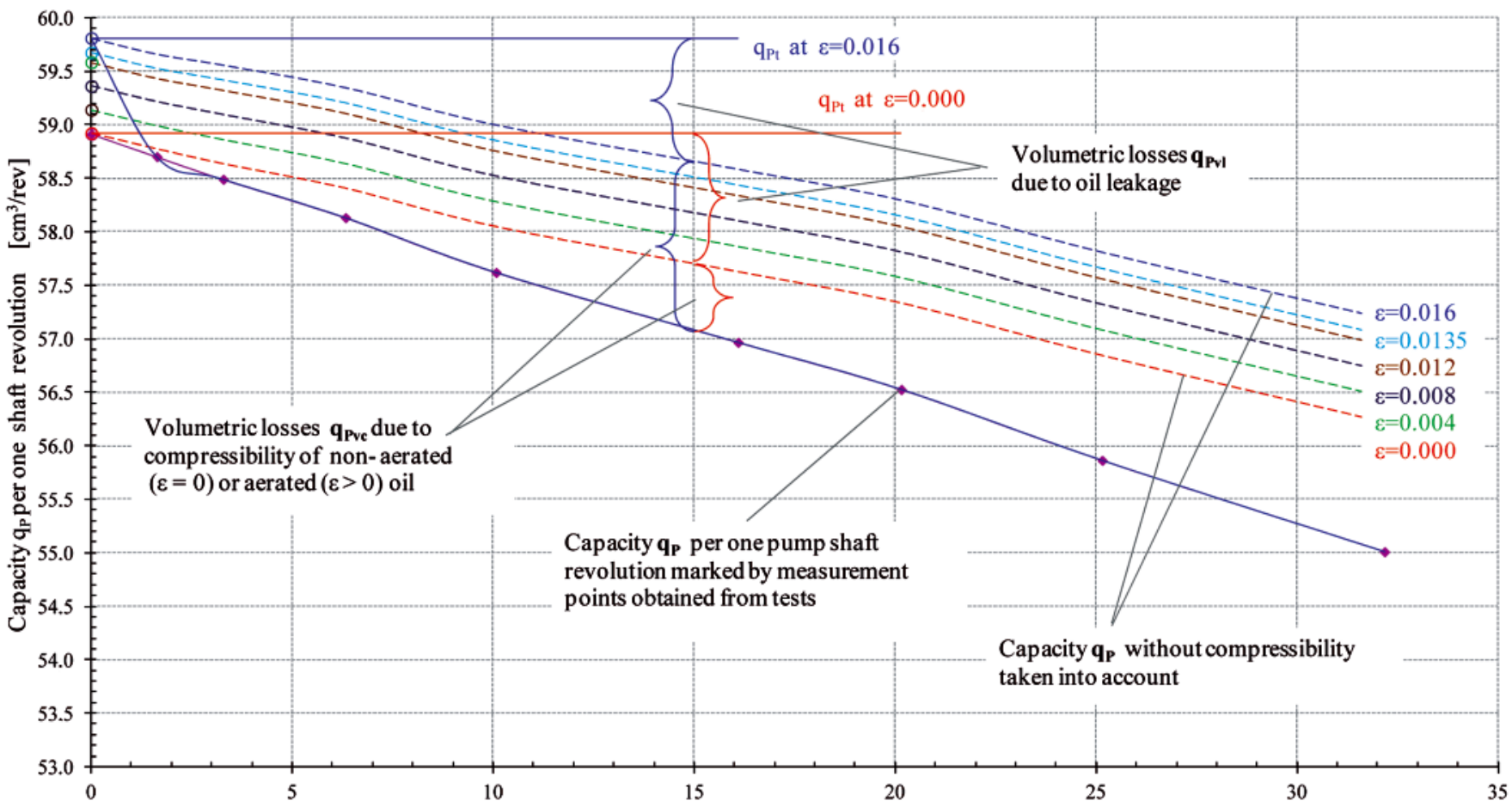

Indicated increase $\Delta \mathrm{p}_{\mathrm{Pi}}$ of pressure $[\mathrm{MPa}]$

Fig. 6. Dependence of pump capacity $q_{P}$ per one shaft revolution on the indicated increase $\Delta p_{P_{i}}$ of pressure in the working chambers, at the coefficients $b_{P}=0.225$ and $b_{P}=1$ of pump capacity; the values $q_{P_{0}}$ of geometrical working volume and $q_{P_{t}}$ of theoretical working volume per one shaft revolution (determined at $\Delta p_{P i}=0$ ) and subdivision of the intensity $q_{P v}=q_{P V l}+q_{P v c}$ of volumetric losses per one shaft revolution into volumetric losses $q_{P v l}$ due to oil leakage in the chambers and volumetric losses $q_{P v C}$ due to compressibility of non-aerated (or aerated) oil dependent on the value of oil aeration coefficient $\varepsilon$ ( $\varepsilon=0$ to 0.016); viscosity coefficient $v / v_{n}=1$, oil temperature $\vartheta=43^{\circ} \mathrm{C}$ (pump of the HYDROMATIK A7V.DR.1.R.P.F.00 type)

As shown in Fig. 6, the pump theoretical working capacity $\mathrm{q}_{\mathrm{Pt}}$, determined by approximation at point $\Delta \mathrm{p}_{\mathrm{Pi}}=0$ of the line $\mathrm{q}_{\mathrm{p}}=\mathrm{f}\left(\Delta \mathrm{p}_{\mathrm{Pi}}\right)$ obtained from tests and taking into account the liquid compressibility, as well as the line $\left(\mathrm{q}_{\mathrm{p} \text { without compressibility }}=\right.$ $\left.=\mathrm{q}_{\mathrm{Pvc}}+\mathrm{q}_{\mathrm{P}}\right)=\mathrm{f}\left(\Delta \mathrm{p}_{\mathrm{Pi}}\right)$ taking into account the compressibility of non-aerated $(\varepsilon=0)$ oil has practically the same value
$\mathrm{q}_{\mathrm{Pt}}=58.9 \mathrm{~cm}^{3} / \mathrm{rev}$. Approximation of the line $\left(\mathrm{q}_{\mathrm{P} \text { without compressibility }}=\right.$ $\left.=\mathrm{q}_{\mathrm{Pvc}_{\mathrm{v}}}+\mathrm{q}_{\mathrm{P}}\right)=\mathrm{f}\left(\Delta \mathrm{p}_{\mathrm{Pi}}\right)$ at point $\Delta \mathrm{p}_{\mathrm{Pi}}=0$, made with allowing for compressibility of aerated oil, shows the increase of $\mathrm{q}_{\mathrm{pt}}$ practically proportional to oil aeration coefficient $\varepsilon$. This is clearly presented in Fig. 7. For example, with $\varepsilon=0.0135$, takes the value $\mathrm{q}_{\mathrm{Pt}}=59.57 \mathrm{~cm}^{3} / \mathrm{obr}$. 

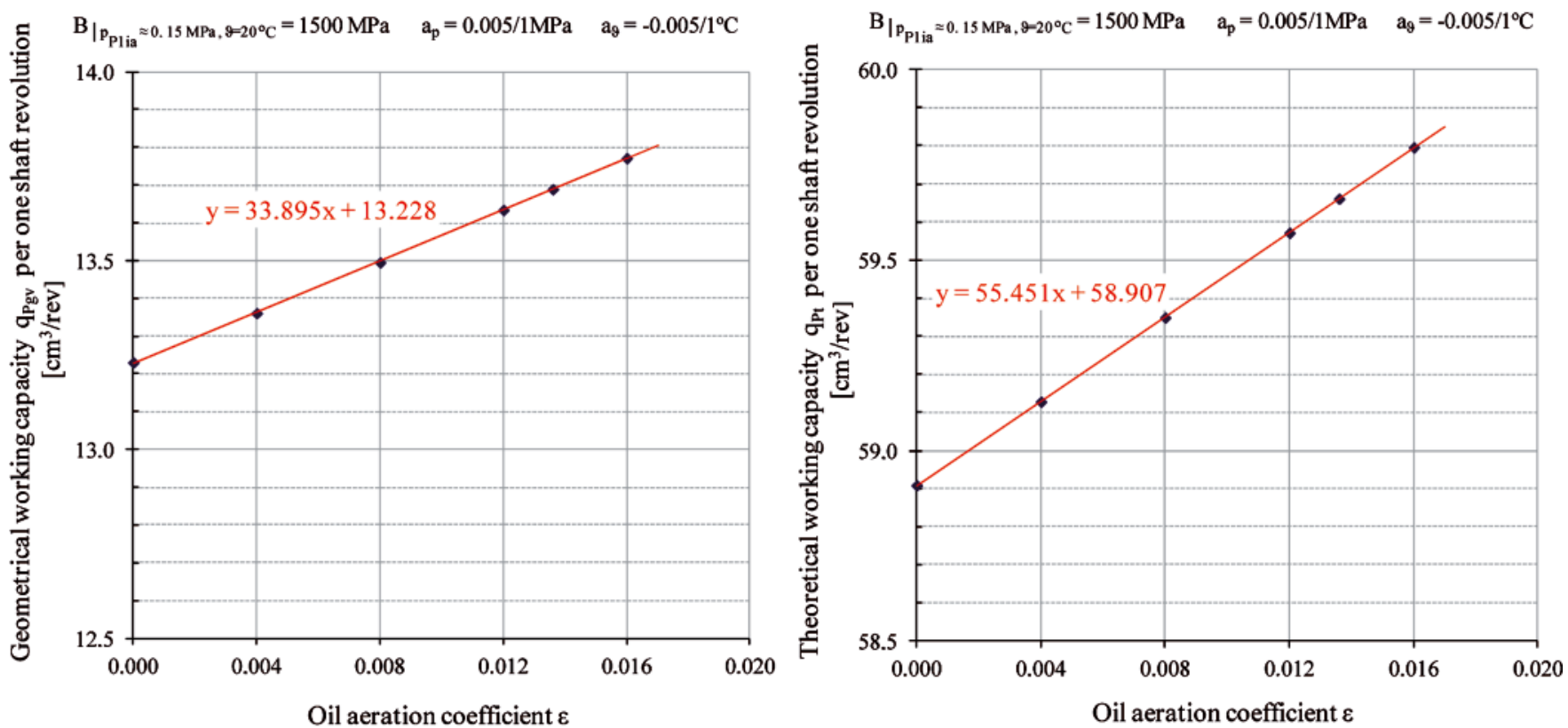

Fig. 7. Effect of evaluation of geometrical working capacity $q_{P g v}$ and theoretical working capacity $q_{P_{t}}$ per one pump shaft revolution resulting from assumption of aeration coefficient $\varepsilon$ of the pump displaced oil; evaluation of $q$ Pgv and qPt (Fig. 7 and Fig. 8) is a result of approximation, at $\Delta p_{P i}=0$, of the relation of pump capacity $q_{P}$ per one shaft revolution to the indicated increase $\Delta p_{P i}$ of pressure in the working chambers taking into account the aerated oil compressibility (at a given oil aeration coefficient $\varepsilon$ ) (pump HYDROMATIK A7V.DR.1.R.P. F.00 type)

Fig. 8a and Fig. 8b present the values of geometrical working capacity $\mathrm{q}_{\mathrm{Pgv}}\left(\mathrm{b}_{\mathrm{p}}=0.225\right)$ and theoretical working capacity $\mathrm{q}_{\mathrm{Pt}}\left(\mathrm{b}_{\mathrm{p}}=1\right)$ per one shaft revolution obtained with different values of the oil viscosity ratio $v / v_{n}$ and also average values $\mathrm{q}_{\mathrm{Pgv}}$ and $\mathrm{q}_{\mathrm{Pt}}$ obtained with assumed. Values of the modulus of liquid volume elasticity $\mathrm{B}=\infty, \mathrm{B}=1500 \mathrm{MPa}$, with assumed values of the oil aeration coefficient $\varepsilon=0$, $\varepsilon=0.008$ and $\varepsilon=0.0135$

\section{RESULTS OF THE VOLUMETRIC LOSS INVESTIGATIONS}

Fig. 9a and $9 \mathrm{~b}$ present the subdivision of volumetric losses $\mathrm{q}_{\mathrm{Pv}}=\mathrm{f}\left(\Delta \mathrm{p}_{\mathrm{Pi}}\right)$ per one shaft revolution into losses $\mathrm{q}_{\mathrm{Pvc}}=\mathrm{f}\left(\Delta \mathrm{p}_{\mathrm{Pi}}\right)$ due to oil compressibility and losses $\mathrm{q}_{\mathrm{Pvl}}=\mathrm{f}\left(\Delta \mathrm{p}_{\mathrm{Pi}}\right)$ due to oil leakage with different values of oil aeration coefficient $\varepsilon$ in the pump, with geometrical working capacity $\mathrm{q}_{\mathrm{Pgv}}$ and theoretical working capacity $\mathrm{q}_{\mathrm{Pt}}$ per one shaft revolution. The figures show, with different values of the aeration coefficient $\varepsilon$, unchanging characteristics of the losses $\mathrm{q}_{\mathrm{Pvl}}=\mathrm{f}\left(\Delta \mathrm{p}_{\mathrm{Pi}}\right)$ due to oil leakage and changing characteristics of the losses $\mathrm{q}_{\mathrm{Pvc}}=\mathrm{f}\left(\Delta \mathrm{p}_{\mathrm{Pi}}\right)$ due to oil compressibility, and also characteristics $\left(\mathrm{q}_{\mathrm{Pv}}=\mathrm{q}_{\mathrm{Pvl}}+\mathrm{q}_{\mathrm{Pvc}}\right)$ $=\mathrm{f}\left(\Delta \mathrm{p}_{\mathrm{Pi}}\right)$ of the volumetric losses $\mathrm{q}_{\mathrm{Pv}}=\mathrm{f}\left(\Delta \mathrm{p}_{\mathrm{Pi}}\right)$ in the pump as a sum of the losses $\mathrm{q}_{\mathrm{Pvl}}=\mathrm{f}\left(\Delta \mathrm{p}_{\mathrm{Pi}}\right)$ due to leakage and the losses $\mathrm{q}_{\mathrm{Pvc}}=\mathrm{f}\left(\Delta \mathrm{p}_{\mathrm{Pi}}\right)$ due to oil compressibility.

Fig. 10a and Fig. 10b present the dependence of volumetric losses $\mathrm{q}_{\mathrm{Pv}}$ per one shaft revolution (with the assumption of $\mathrm{B}$ $=\infty$ ) or the dependence of volumetric losses $\mathrm{q}_{\mathrm{Pvl}}$ per one shaft revolution due to oil leakage (with the assumption of $\mathrm{B}=1500$ $\mathrm{MPa}, \mathrm{a}_{\mathrm{p}}=0.005 / 1 \mathrm{MPa}, \mathrm{a}_{\vartheta}=-0.005 / 1^{\circ} \mathrm{C}$ ) on the indicated increase $\Delta \mathrm{p}_{\mathrm{Pi}}$ of pressure in the pump working chambers, with different values $v / v_{\mathrm{n}}$ of oil viscosity ratio, with coefficient $b_{\mathrm{P}}=0.225$ and $b_{\mathrm{P}}=1$ of pump capacity $\mathrm{q}_{\mathrm{Pgv}}$ per one shaft revolution. With taking into account the oil compressibility, losses due to oil leakage in the pump working chambers appear evidently smaller.

Fig. 11a and Fig. 11b present the high share of volumetric losses $\mathrm{q}_{\mathrm{Pvc}}$ per one shaft revolution due to compressibility of non-aerated $(\varepsilon=0)$ and aerated $(\varepsilon=0.0135)$ oil as a component of the volumetric losses $\mathrm{q}_{\mathrm{Pv}}=\mathrm{q}_{\mathrm{Pvl}}+\mathrm{q}_{\mathrm{Pvc}}$ in the tested pump. With coefficient of pump capacity $b_{P}=1$ and coefficient of non-aerated oil $\varepsilon=0$, that share was in the 30 to $40 \%$ range. With the aeration coefficient $\varepsilon=0.0135$, the share changes from $40 \div 50 \%$ to $80 \div 90 \%$. With coefficient $b_{P}=0.225$ of pump capacity, the share is a little lower but still high.

Fig. 12 presents the volumetric losses $\mathrm{q}_{\mathrm{Pvl}}$ per one shaft revolution due to oil leakage as a dependence on the indicated increase $\Delta \mathrm{p}_{\mathrm{Pi}}$ of pressure in the working chambers with different values of the pump capacity coefficient $b_{p}$ and different values of oil viscosity ratio $v / v_{n}$. Decreasing oil viscosity $v$ has a clear influence on the increase of leakage in the pump, but change of pump capacity coefficient $b_{\mathrm{P}}$ has practically no influence on leakage in the chambers.

\section{CONCLUSIONS}

1. Ability of determining the aeration of working liquid and resulting liquid compressibility makes it possible to determine the volumetric losses $\mathrm{q}_{\mathrm{Pv}}$ in the pump working chambers and subdivision of the losses into losses $\mathrm{q}_{\mathrm{Pvl}}$ due to leakage in the pump chambers and losses $\mathrm{q}_{\mathrm{Pvc}}$ due to liquid compressibility in the chambers which are not connected with displacement pump construction.

2. The influence of liquid compressibility on the evaluation of volumetric losses in the pump with the oil aeration coefficient $\varepsilon=0.0135$ was remarkable. Losses due to liquid compressibility amounted to $30 \div 90 \%$ of volumetric losses depending on the value of increase $\Delta \mathrm{p}_{\mathrm{Pi}}$ of pressure in the working chambers, the oil viscosity ratio $v / v_{n}$ and the pump capacity coefficient $b_{P}$

3. Knowledge of the compressibility of non-aerated liquid makes it possible to determine the volumetric losses due to leakage in the pump working chambers.

4. Volumetric losses due to leakage and volumetric losses due to liquid compressibility must be clearly separated and only the losses due to leakage should be taken into account for pump evaluation. 
$\bullet 0.419 \bullet 0.541 \bullet 0.762 \bullet 1.000 \bullet 1.357 \bullet 1.885 \bullet 2.629 \bullet 3.472$

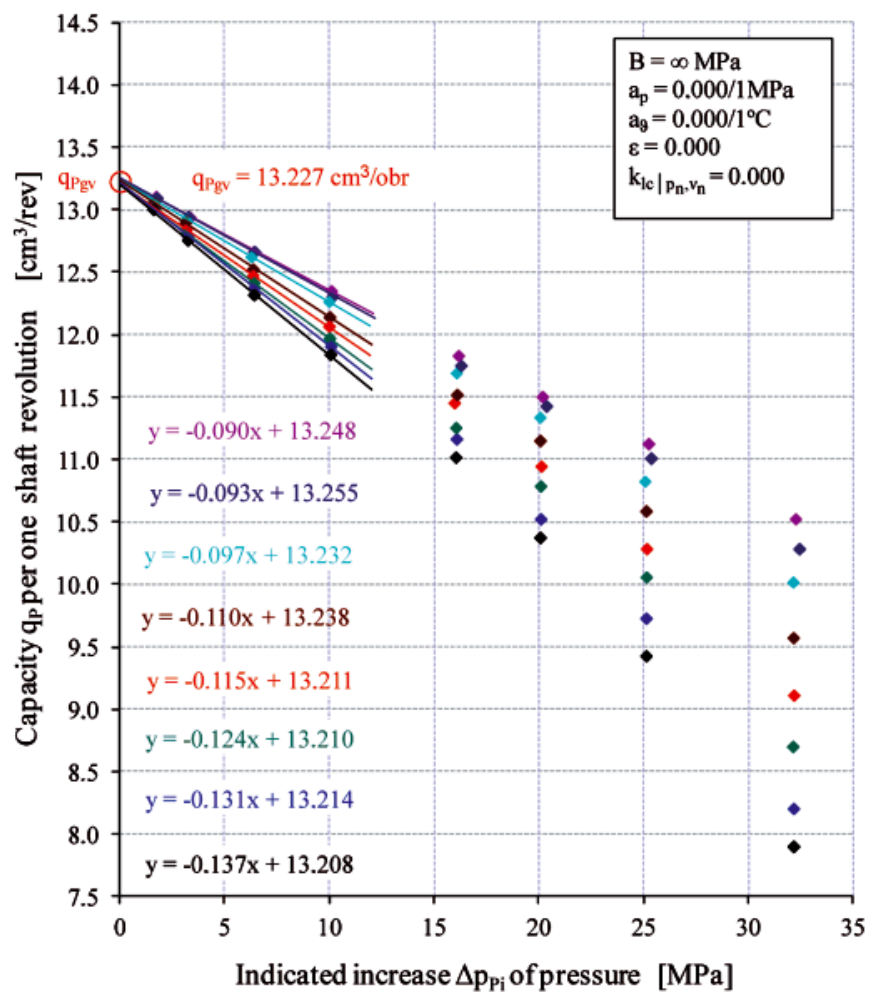

$\bullet 0.419 \bullet 0.541 \bullet 0.762 \bullet 1.000 \bullet 1.357 \bullet 1.885 \bullet 2.629 \bullet 3.472$

$\mathbf{b}_{\mathrm{P}}=\mathbf{0 . 2 2 7} \quad$ Oil viscosity ratio $\mathrm{v} / \mathrm{v}_{\mathrm{n}} \quad v_{\mathrm{n}}=35 \mathrm{~mm}^{2} \mathrm{~s}^{-1}$

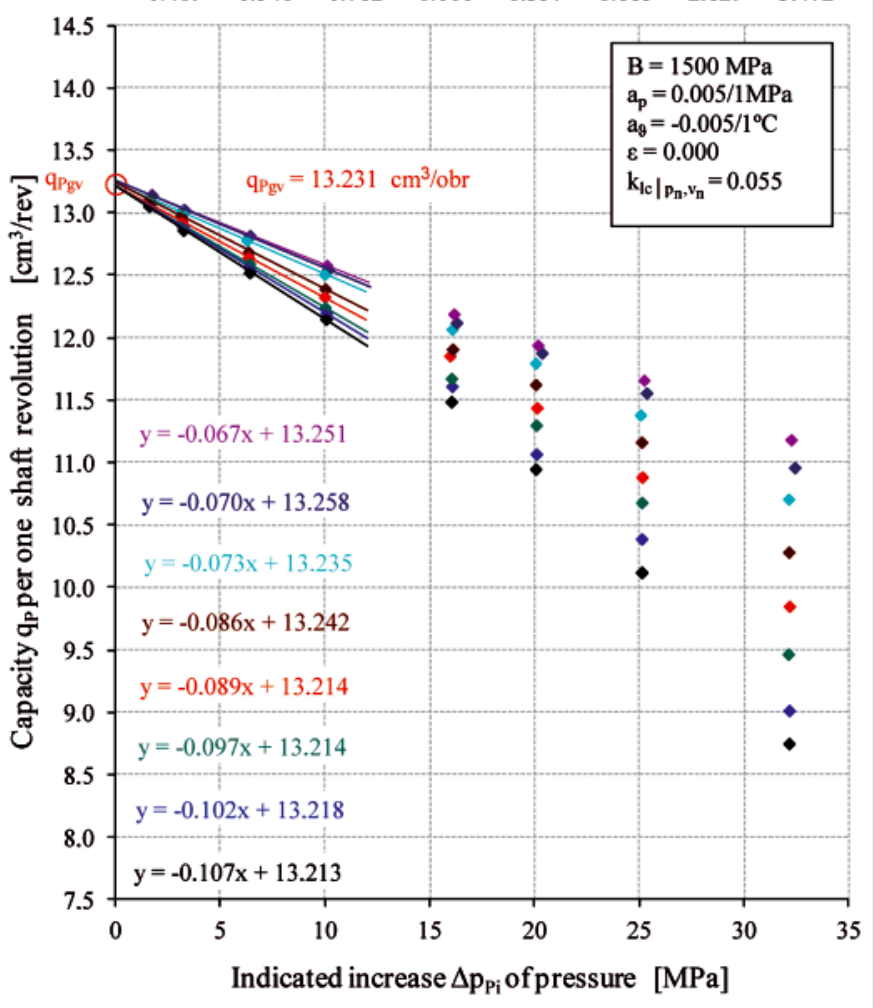

$\bullet 0.419 \bullet 0.541 \bullet 0.762 \bullet 1.000 \bullet 1.357 \bullet 1.885 \bullet 2.629 \bullet 3.472$

$\mathbf{b}_{\mathrm{P}}=\mathbf{0 . 2 3 2} \quad$ Oil viscosity ratio $\mathrm{v} / \mathrm{v}_{\mathrm{n}} \quad v_{\mathrm{n}}=35 \mathrm{~mm}^{2} \mathrm{~s}^{-1}$
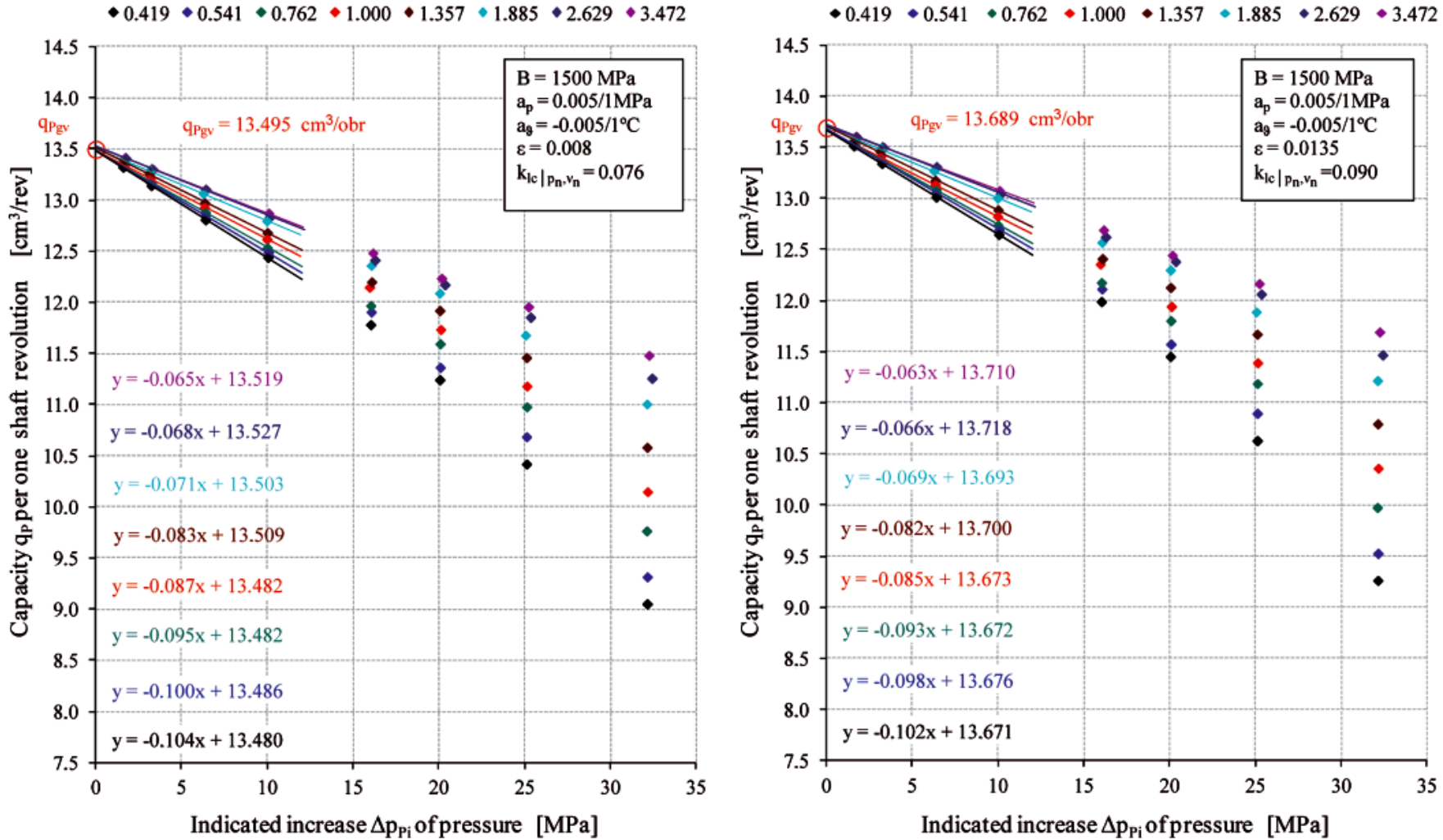

Fig. 8a. Determination of the pump geometrical variable working capacity $q_{P g v}\left(q_{P g v}=b_{P} \cdot q_{P t}\right)$ and the value of pump capacity coefficient $b_{P}$ from the dependence of pump capacity $q_{p}$ per one shaft revolution on the indicated increase $\Delta p_{P_{i}}$ of pressure in the pump working chambers with different values of oil viscosity ratio $v / v_{n}$ and average value of $q_{P g v}$; assumed values $B=\infty$ and $B=1500 \mathrm{MPa}$, assumed values $\varepsilon=0, \varepsilon=0.008, \varepsilon=0.0135$, $b_{P}=0.225$ to 0.232 (pump HYDROMATIK A7V.DR.1.R.P. F.00 type) 
$\bullet 0.419 \bullet 0.541 \bullet 0.762 \bullet 1.000 \bullet 1.357 \bullet 1.885 \bullet 2.629$

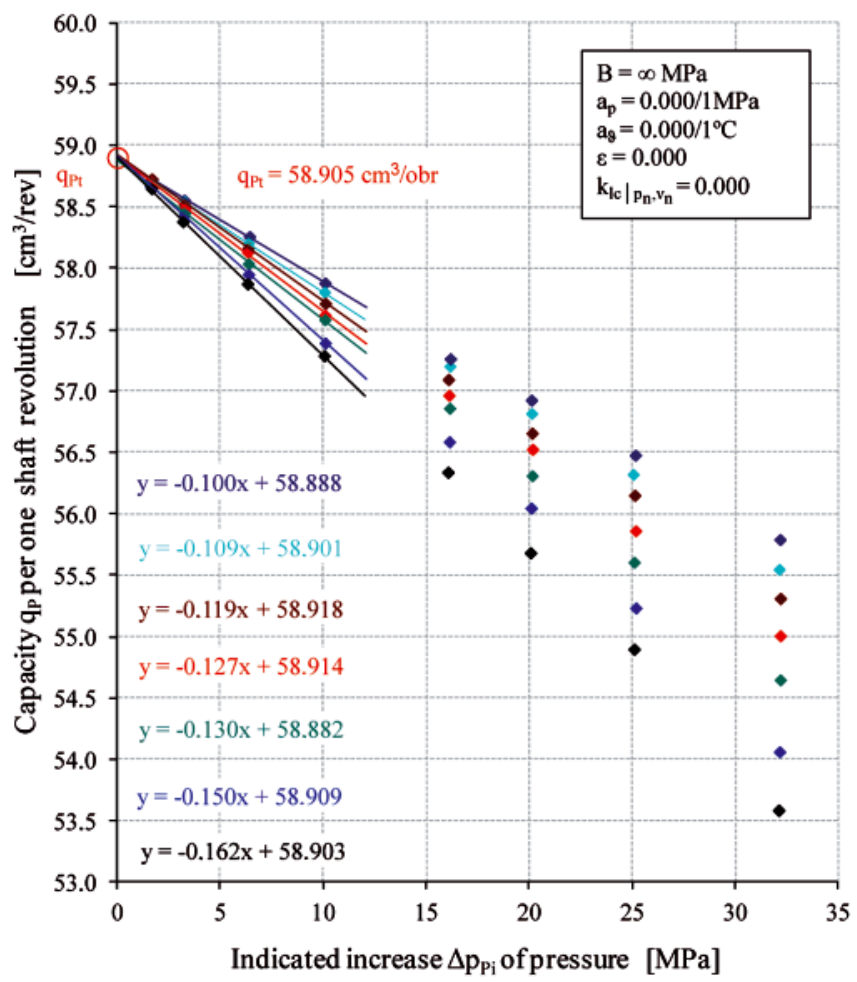

$b_{\mathrm{P}}=1.000$

Oil viscosity ratio $v / v_{\mathrm{n}}$

$v_{\mathrm{n}}=35 \mathrm{~mm}^{2} \mathrm{~s}^{-1}$

$\bullet 0.419 \bullet 0.541 \bullet 0.762 \bullet 1.000 \bullet 1.357 \bullet 1.885 \bullet 2.629$

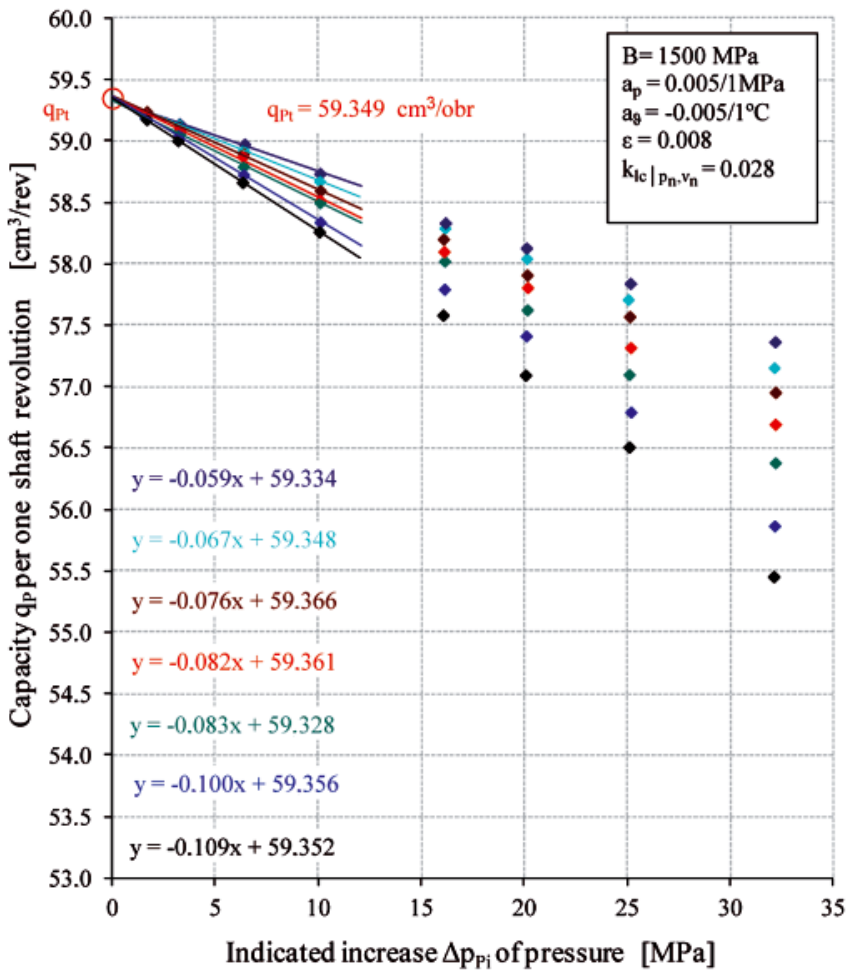

$\bullet 0.419 \bullet 0.541 \bullet 0.762 \bullet 1.000 \bullet 1.357 \bullet 1.885 \bullet 2.629$

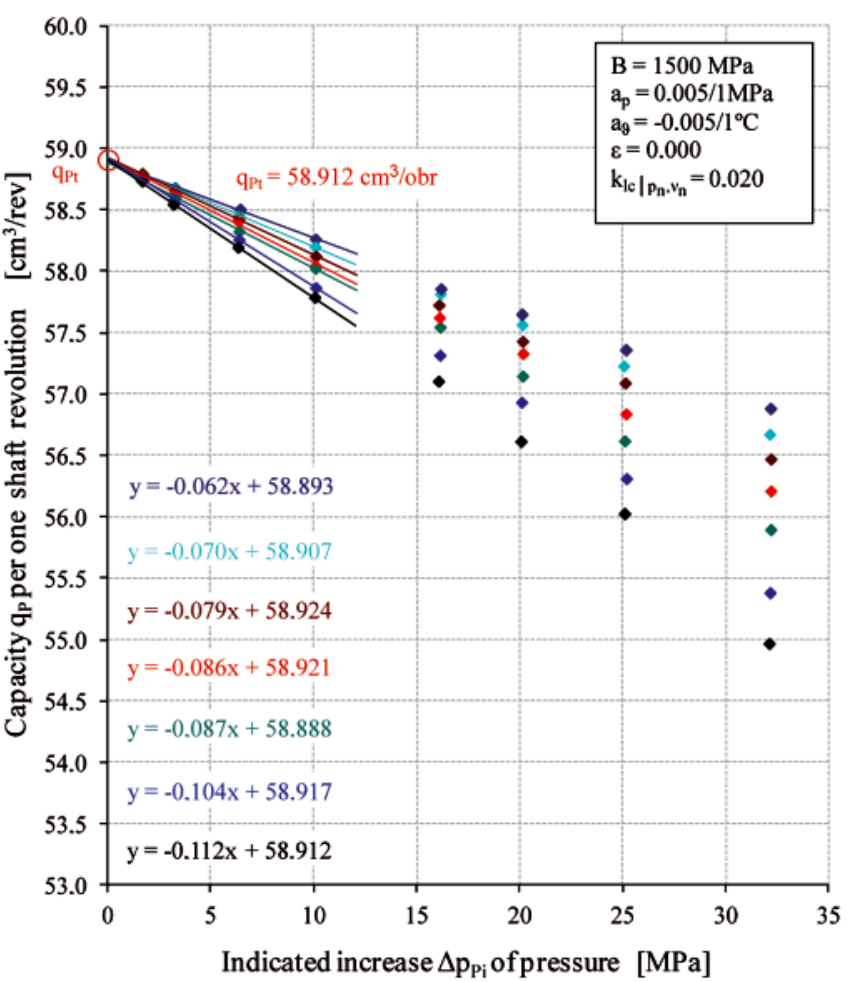

$b_{\mathrm{P}}=\mathbf{1 . 0 0 0} \quad$ Oil viscosity ratio $v / v_{\mathrm{p}}$

$v_{\mathrm{n}}=35 \mathrm{~mm}^{2} \mathrm{~s}^{-1}$

$\bullet 0.419 \bullet 0.541 \bullet 0.762 \bullet 1.000 \bullet 1.357 \cdot 1.885 \bullet 2.629$

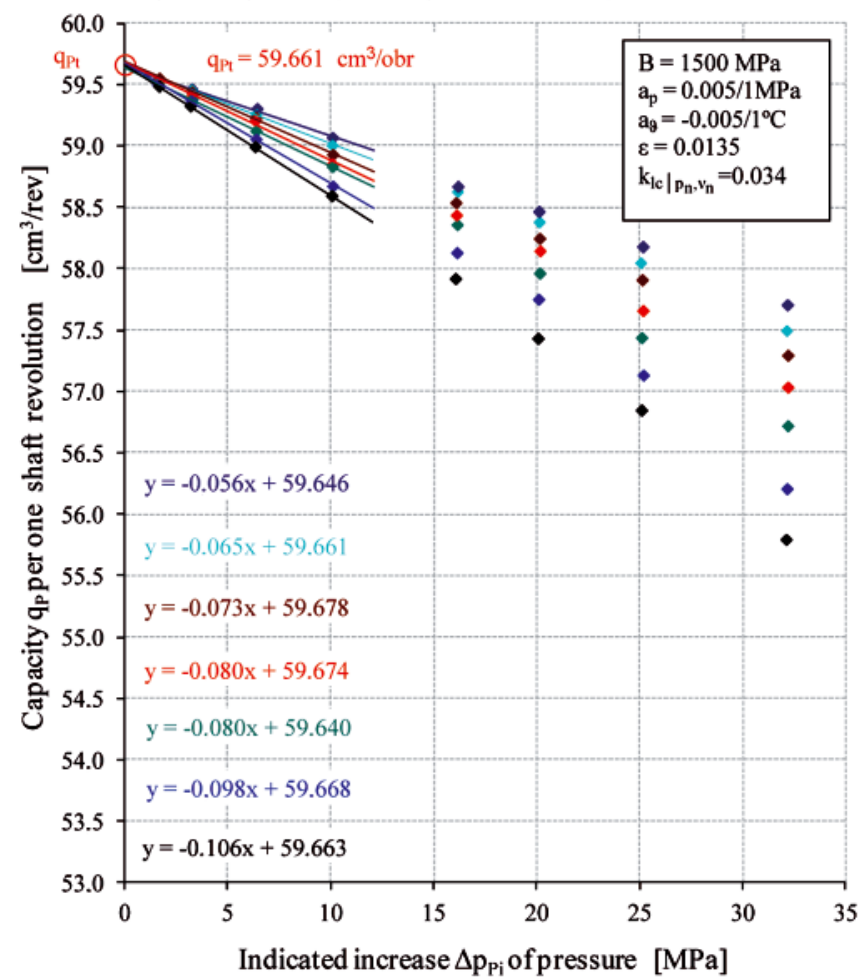

Fig. 8b. Determination of the pump theoretical working capacity $q_{P t}$ (pump capacity coefficient $b_{P}=1$ ) from the dependence of pump capacity $q_{P}$ per one shaft revolution on the indicated increase $\Delta p_{P i}$ of pressure in the pump working chambers, with different values of oil viscosity ratio $v / v_{n}$ and average value of $q_{P t}$; assumed values $B=\infty$ and $B=1500 \mathrm{MPa}$, assumed values $\varepsilon=0, \varepsilon=0.008, \varepsilon=0.0135$ (pump HYDROMATIK A7V.DR.1.R.P. F.00 type) 

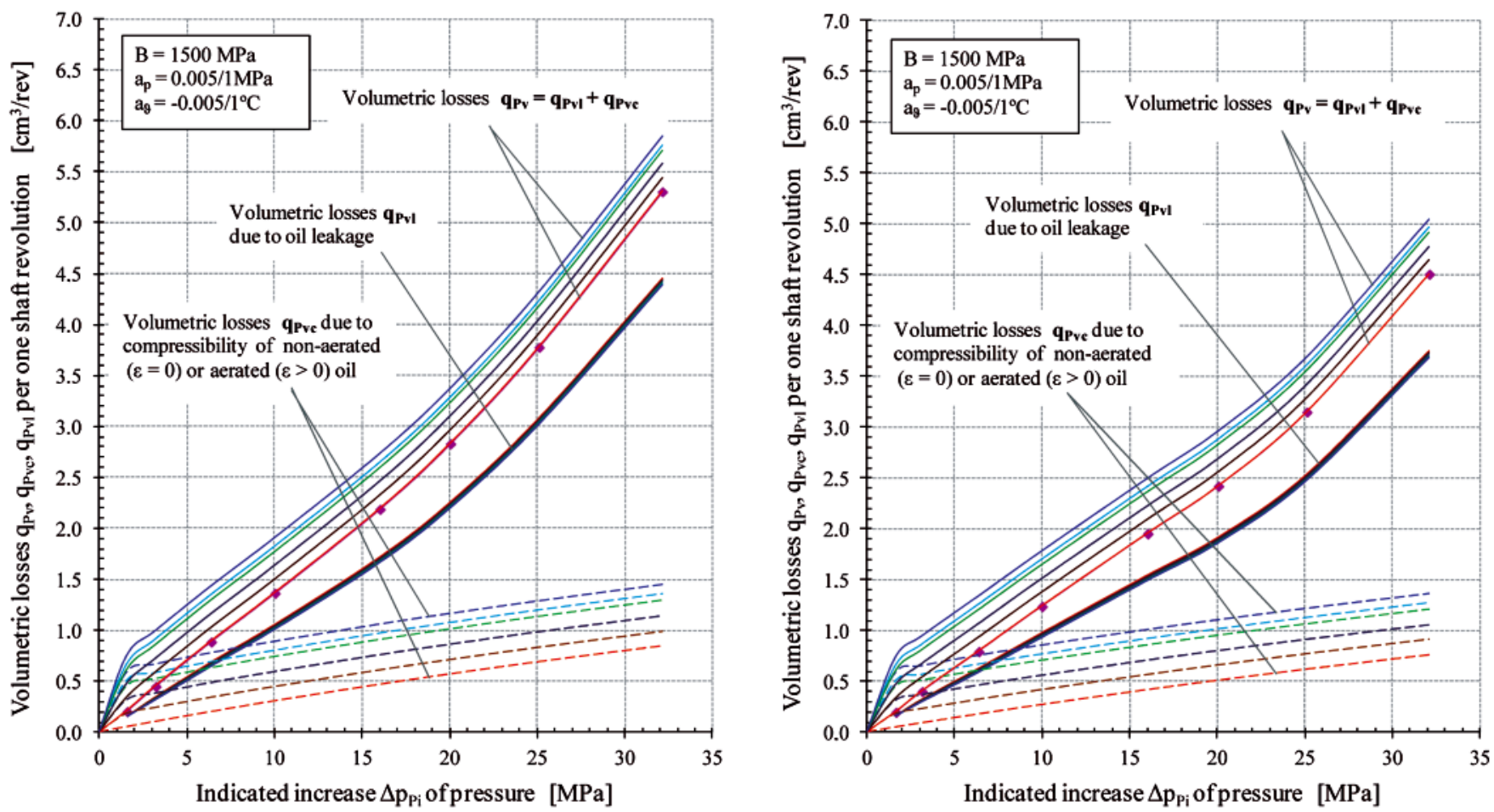

$b_{P}=0.225 \mathrm{v} / v_{\mathrm{n}}=1.000$ Oil aeration coefficient $\varepsilon$

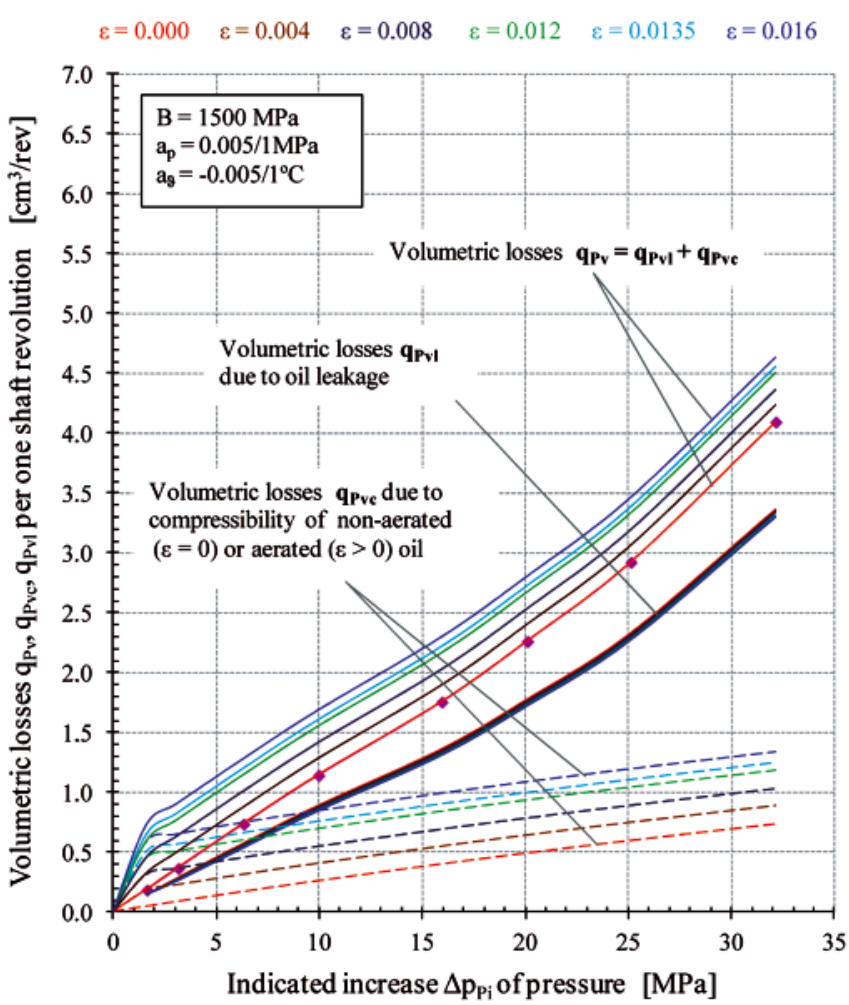

\section{$b_{\mathrm{P}}=\mathbf{0 . 2 2 5} \quad \mathrm{v} / \mathrm{v}_{\mathrm{n}}=\mathbf{2 . 6 2 9}$}

\section{Oil aeration coefficient $\varepsilon$}

$v_{\mathrm{n}}=35 \mathrm{~mm}^{2} \mathrm{~s}^{-1}$ $\varepsilon=0.000 \quad \varepsilon=0.004 \quad \varepsilon=0.008 \quad \varepsilon=0.012 \quad \varepsilon=0.0135 \quad \varepsilon=0.016$

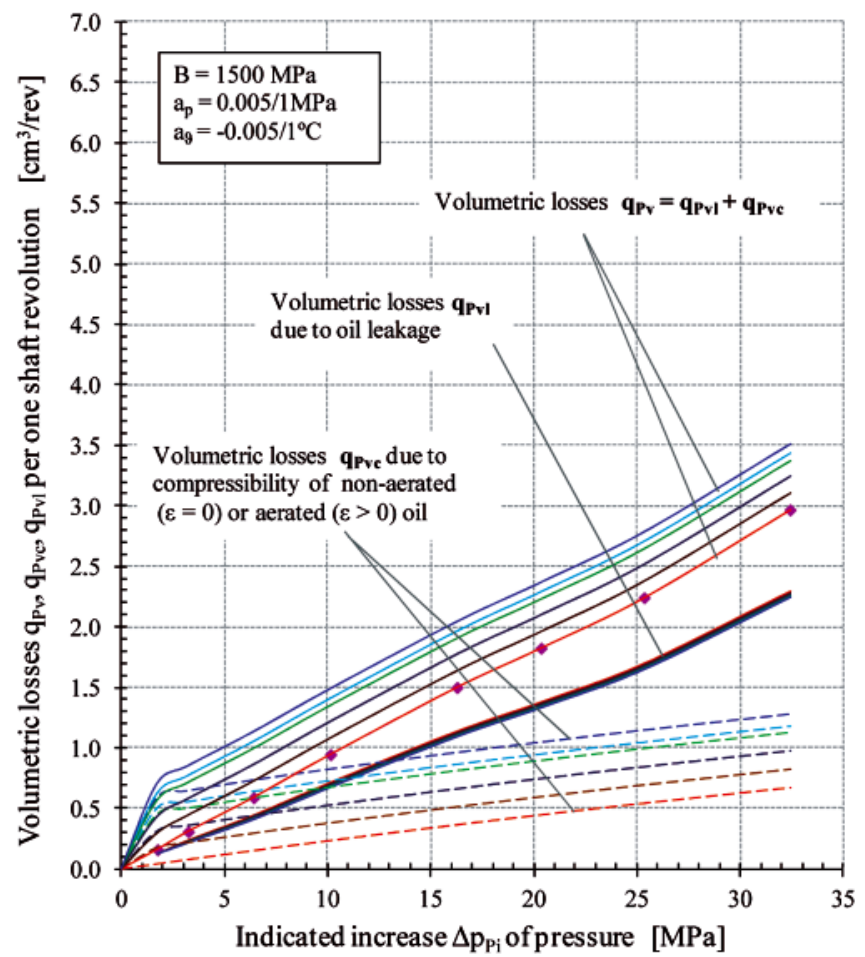

Fig. 9a. Subdivision of volumetric losses $q_{P v}=f\left(\Delta p_{P i}\right)$ per one shaft revolution in the pump working chambers into losses $q_{P v c}=f\left(\Delta p_{P i}\right)$ due to oil compressibility and losses $q_{P v l}=f\left(\Delta p_{P_{i}}\right)$ due to oil leakage at different values of oil aeration coefficient $\varepsilon$ and different values of oil viscosity ratio $v / v_{n}$ in the tested pump with the pump geometrical working capacity $q_{P g v}\left(b_{P}=0.225\right)$ (pump HYDROMATIK A7V.DR.1.R.P.F.00 type) 
Oil aeration coefficient $\varepsilon$

$\varepsilon=0.016$

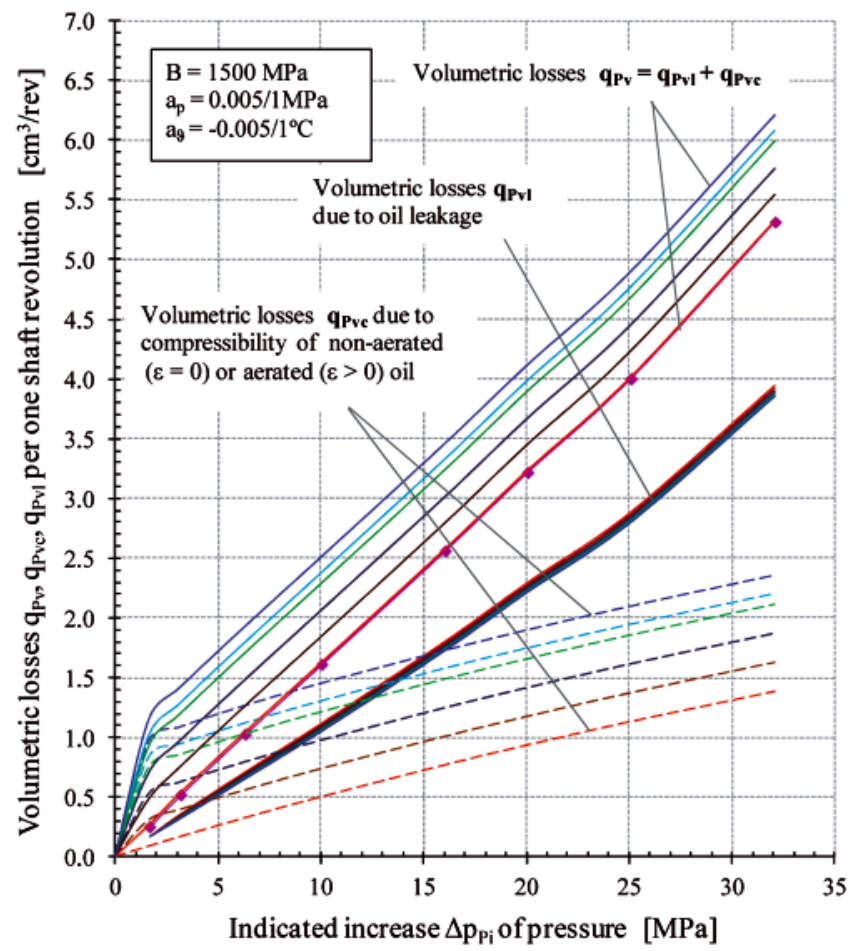

\section{$b_{P}=1,000 v / v_{n}=1,000$}

Oil aeration coefficient $\varepsilon$

$v_{\mathrm{n}}=35 \mathrm{~mm}^{2} \mathrm{~s}^{-1}$

$\varepsilon=0.000 \quad \varepsilon=0.004 \quad \varepsilon=0.008 \quad \varepsilon=0.012 \quad \varepsilon=0.0135 \quad \varepsilon=0.016$

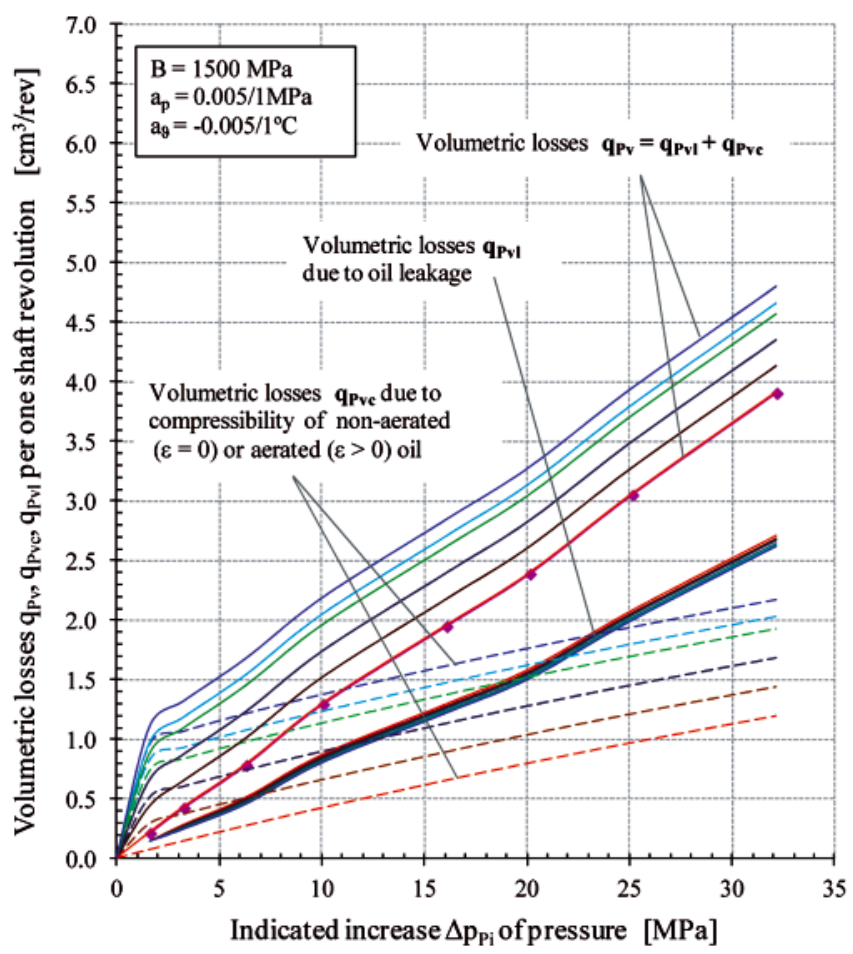

Oil aeration coefficient $\varepsilon$

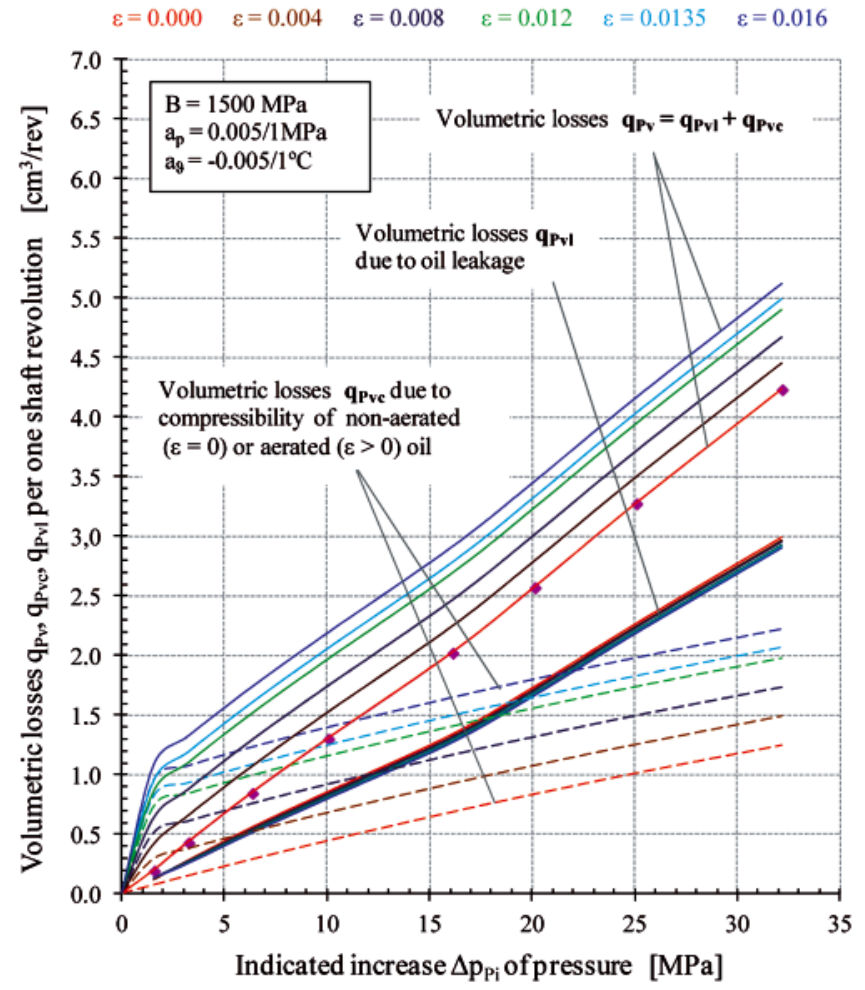

$b_{P}=1.000 v / v_{n}=2.629$

Oil aeration coefficient $\varepsilon$

$v_{\mathrm{n}}=35 \mathrm{~mm}^{2} \mathrm{~s}^{-1}$ $\varepsilon=0.000 \quad \varepsilon=0.004 \quad \varepsilon=0.008 \quad \varepsilon=0.012 \quad \varepsilon=0.0135 \quad \varepsilon=0.016$

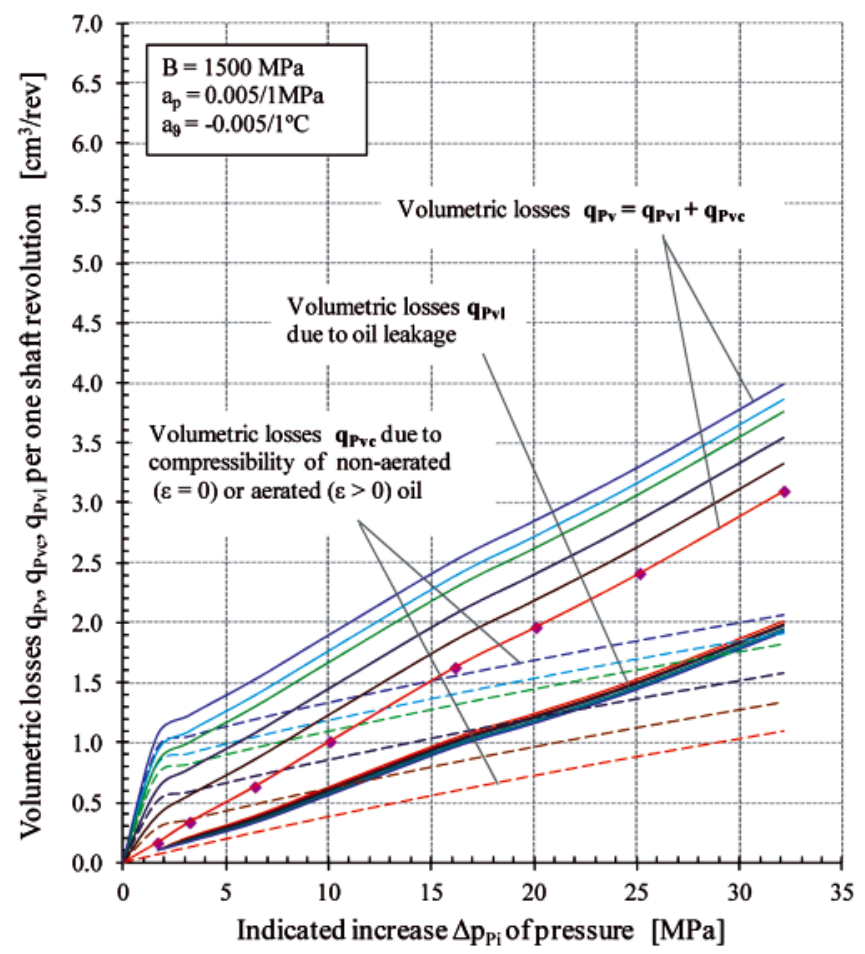

Fig. 9b. Subdivision of volumetric losses $q_{P v}=f\left(\Delta p_{P i}\right)$ per one shaft revolution in the pump working chambers into losses $q_{P v c}=f\left(\Delta p_{P i}\right)$ due to oil compressibility and losses $q_{P v l}=f\left(\Delta p_{P i}\right)$ due to oil leakage at different values of oil aeration coefficient $\varepsilon$ and different values of oil viscosity ratio $v / v_{n}$ in the tested pump with the pump theoretical working capacity $q_{P t}\left(b_{P}=1\right)$ (pump HYDROMATIK A7V.DR.1.R.P.F.00 type) 

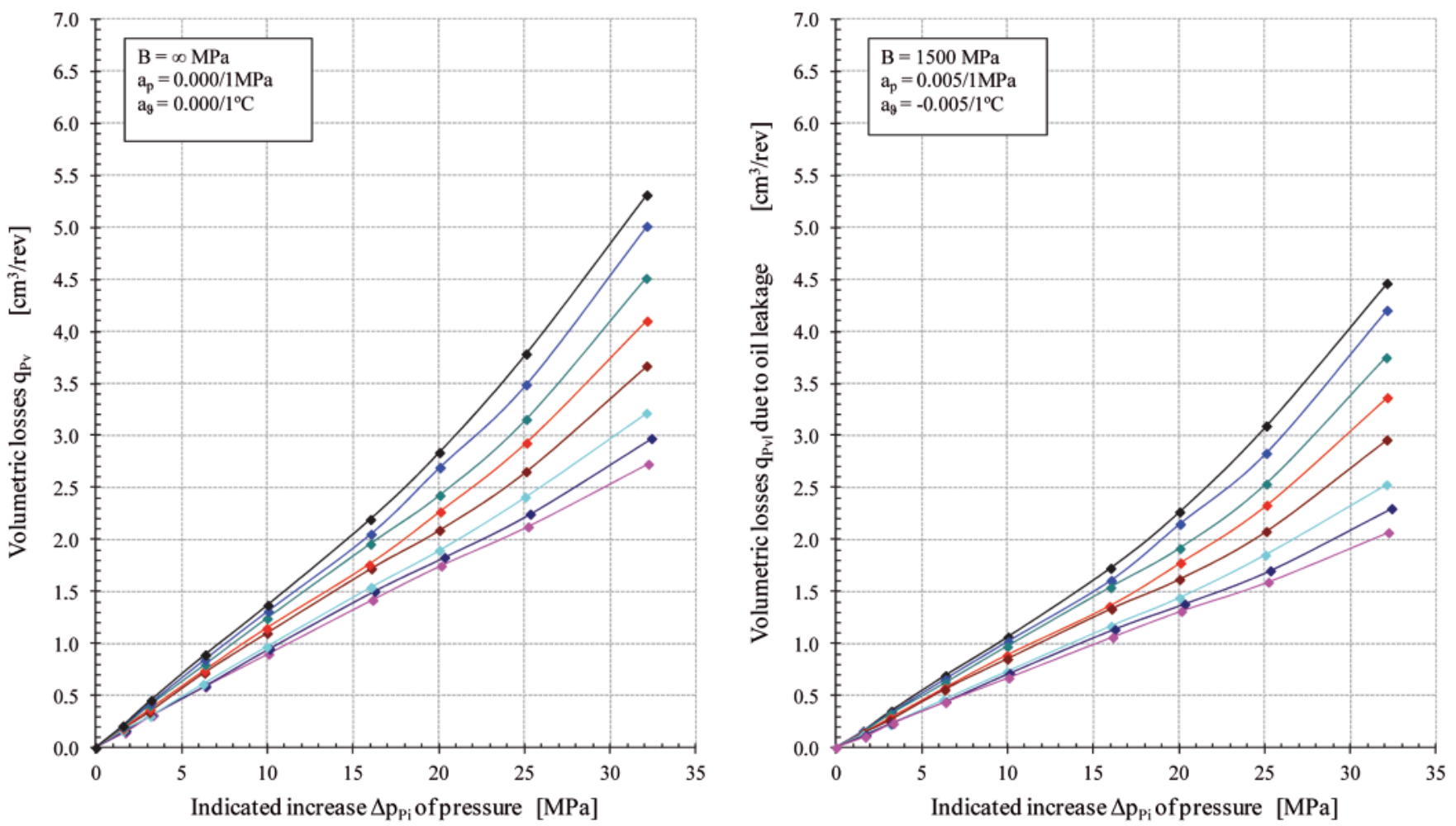

Fig. 10a. Volumetric losses $q_{P v}$ per one shaft revolution (with the assumption $B=\infty$ ) or volumetric losses $q_{P v 1}$ per one shaft revolution due to oil leakage (with the assumption of $B=1500 \mathrm{MPa}, a_{p}=0.005 / 1 \mathrm{MPa}, a_{\vartheta}=-0.005 / 1{ }^{\circ} \mathrm{C}$ ) as dependent on the indicated increase $\Delta p_{P i}$ of pressure in the pump working chambers, with different values of oil viscosity ratio $v / v_{n}$, with coefficient $b_{P}=0.225$ of pump capacity $q_{P g v}$ per one shaft revolution $\left(b_{P}=q_{P g} / q_{P t}\right)($ pump HYDROMATIK A7V.DR.1.R.P. F.00 type)

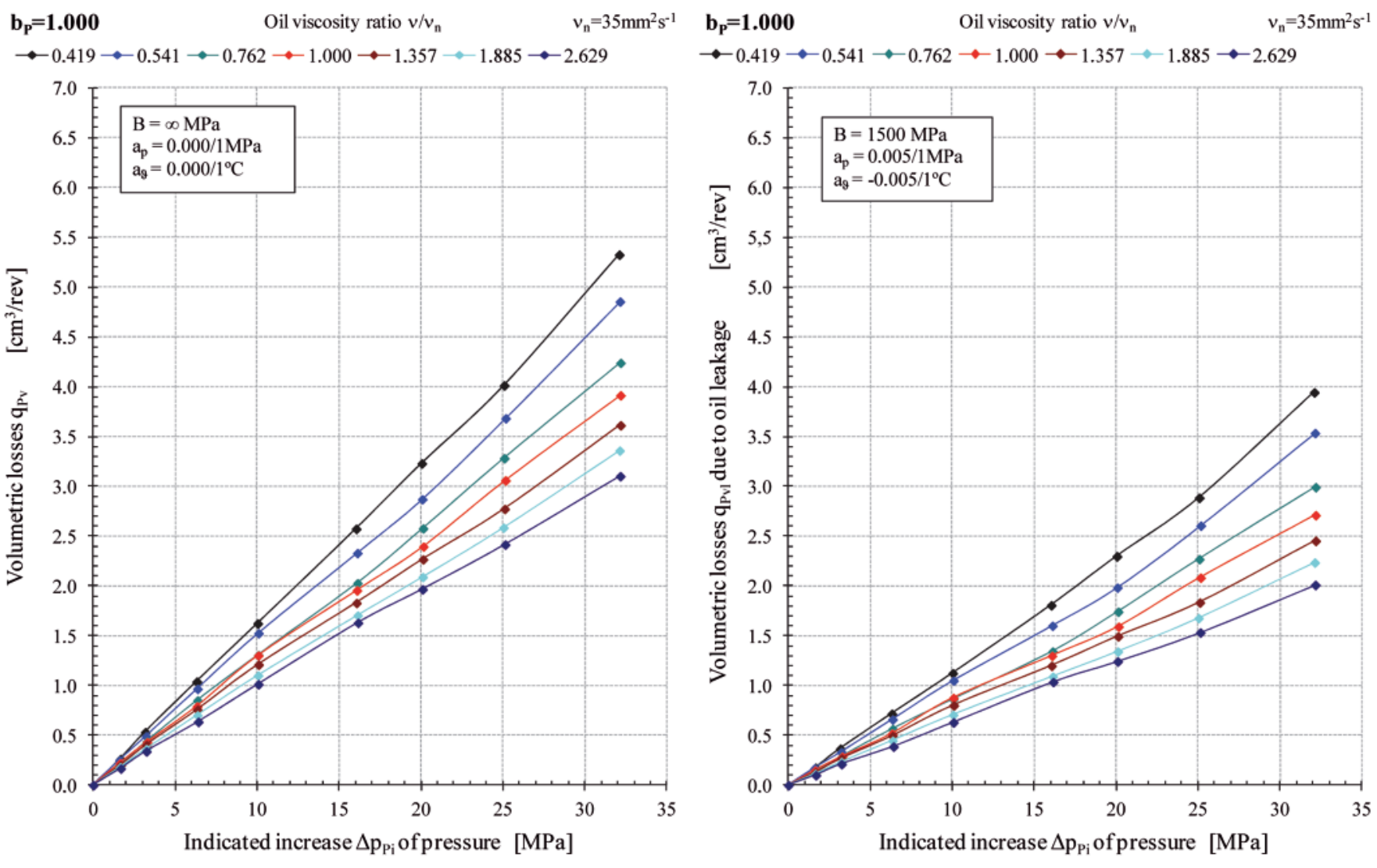

Fig. 10b. Volumetric losses $q_{P v}$ per one shaft revolution (with the assumption $B=\infty$ ) or volumetric losses $q_{P v l}$ per one shaft revolution due to oil leakage (with the assumption of $B=1500 \mathrm{MPa}, a_{p}=0.005 / 1 \mathrm{MPa}, a_{\vartheta}=-0.005 / 1{ }^{\circ} \mathrm{C}$ ) as dependent on the indicated increase $\Delta p_{P i}$ of pressure in the pump working chambers, with different values of oil viscosity ratio $v / v_{n}$, with coefficient $b_{P}=1$ of pump capacity $q_{P g v}$ per one shaft revolution $\left(b_{P}=q_{P g} / q_{P t}\right)($ pump 
$\mathbf{b}_{\mathrm{P}}=\mathbf{0 . 2 2 5} \quad$ Oil viscosity ratio $v / v_{\mathrm{n}} \quad v_{\mathrm{n}}=35 \mathrm{~mm}^{2} \mathrm{~s}^{-1} \quad \mathbf{b}_{\mathrm{P}}=\mathbf{0 . 2 2 5} \quad v_{\mathrm{n}}=35 \mathrm{~mm}^{2} \mathrm{~s}^{-1}$

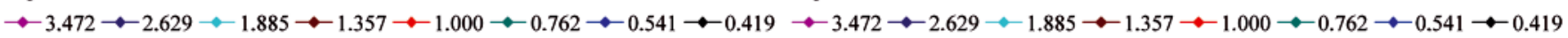
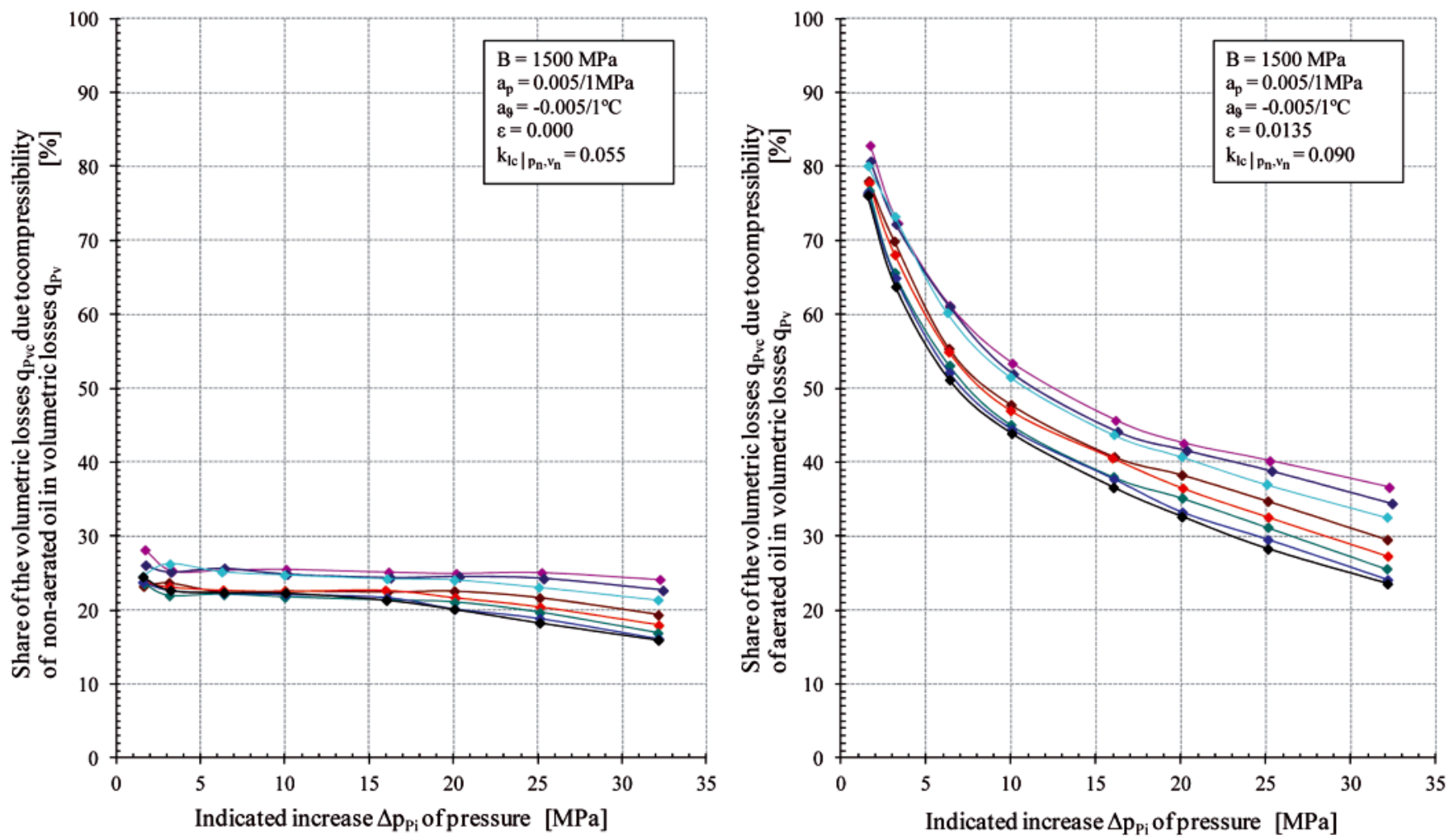

Fig. 11a. Share of the volumetric losses $q_{P v c}$ per one shaft revolution due to compressibility of non-aerated $(\varepsilon=0)$ and aerated $(\varepsilon=0.0135)$ oil in the pump volumetric losses $q_{P v}$, with the pump capacity coefficient $b_{P}=0.225$ (pump HYDROMATIK A7V.DR.1.R.P.F.00 type)
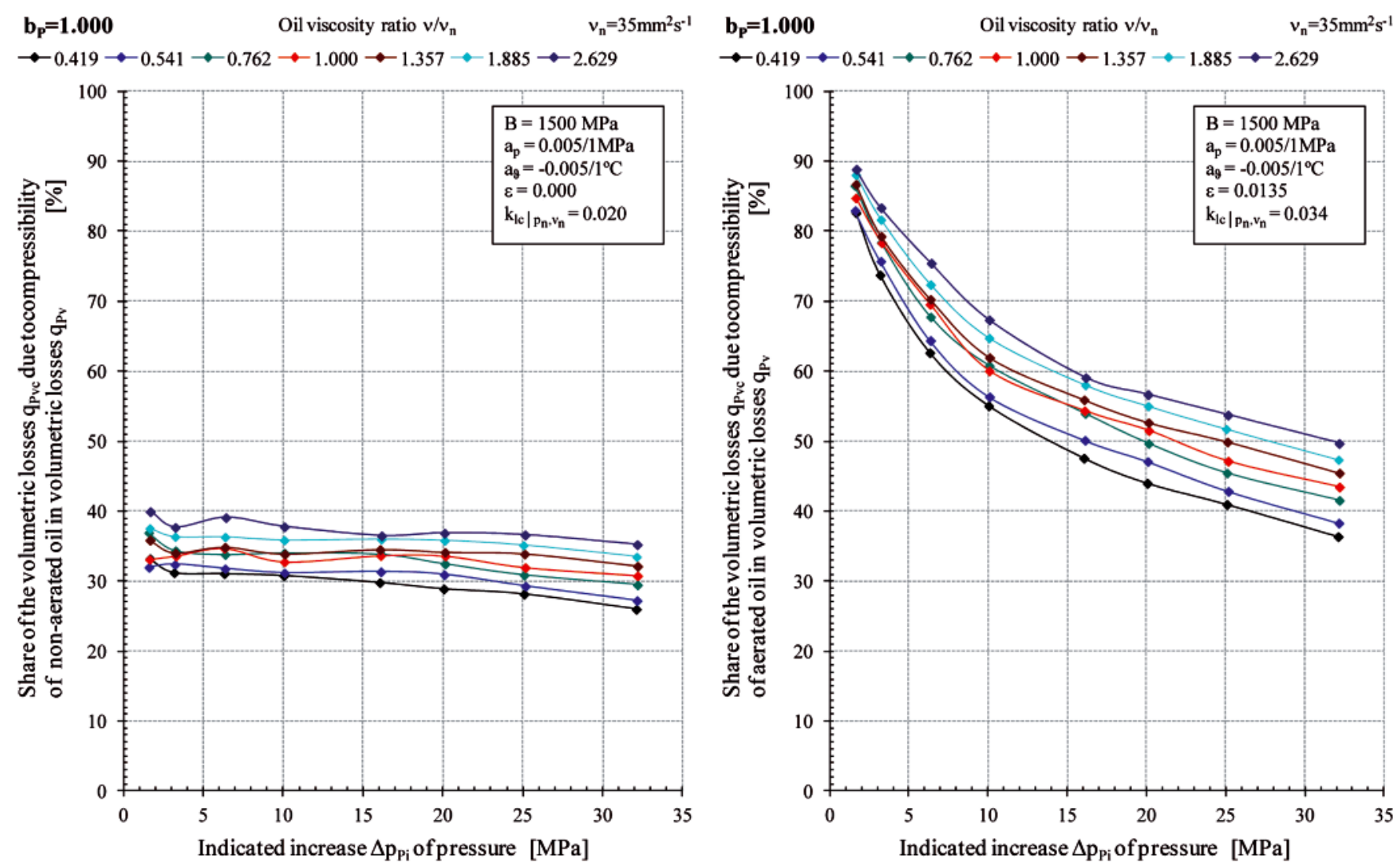

Fig. 11b. Share of the volumetric losses $q_{P v c}$ per one shaft revolution due to compressibility of non-aerated $(\varepsilon=0)$ and aerated $(\varepsilon=0.0135)$ oil in the pump volumetric losses $q_{P v}$, with the pump capacity coefficient $b_{P}=1$ (pump HYDROMATIK A7V.DR.1.R.P.F.OO type) 

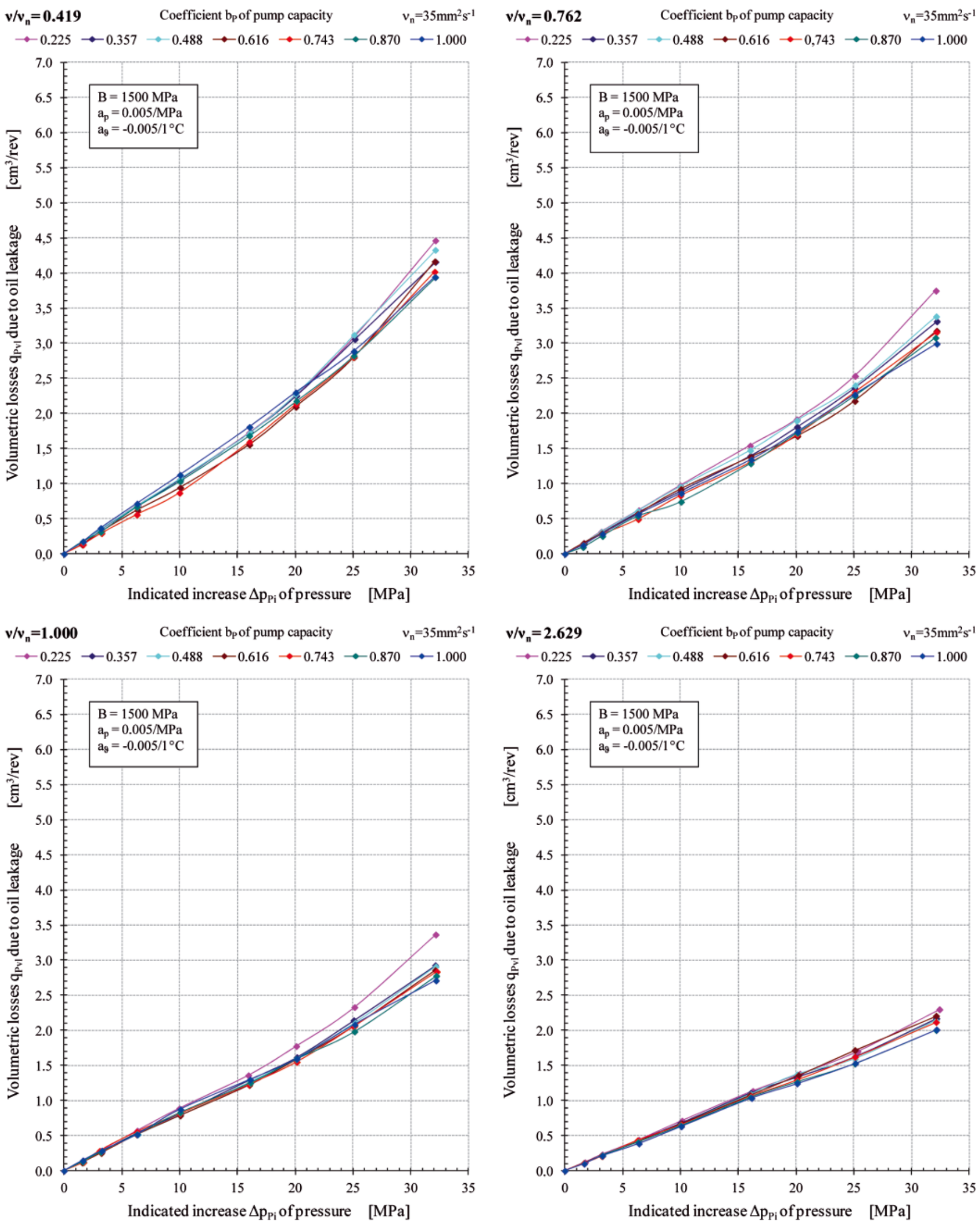

Fig. 12. Volumetric losses $q_{P v l}$ per one shaft revolution due to oil leakage as dependent on the indicated increase $\Delta p_{P i}$ of pressure into the pump working chambers, with different values of pump capacity coefficient $b_{P}$ and different values $v / v_{n}$ ratio of oil viscosity; losses $q_{P v l}$ are practically independent of the pump capacity coefficient $b_{P}$ (pump HYDROMATIK A7V.DR.1.R.P.F.00 type) 


\section{BIBLIOGRAPHY}

1. Koralewski J.: Influence of hydraulic oil viscosity on the volumetric losses in a variable capacity piston pump. Chapter in the monograph: ,Research, design, production and operation of hydraulic systems" (in Polish) Adam Klich, Antoni Kozieł and Edward Palczak editors. „Cylinder” Library. „Komag” Mining Mechanisation Centre, Gliwice 2011

2. Koralewski J.: Influence of hydraulic oil viscosity on the volumetric losses in a variable capacity piston pump. „Napędy i sterowanie", scientific monthly, $9 / 2011$

3. Koralewski J.: Influence of hydraulic oil viscosity on the volumetric losses in a variable capacity piston pump. Polish Maritime Research 3, 2011, Vol. 18

4. Paszota Z.: Effect of the working liquid compressibility on the picture of volumetric and mechanical losses in a high pressure displacement pump used in a hydrostatic drive. Part I Energy losses in a drive system, volumetric losses in a pump//International Scientific-Technical Conference Hydraulics and Pneumatics, Wrocław, 16 - 18 maja 2012/ Ośrodek Doskonalenia Kadr SIMP - Wrocław : ODK SIMP we Wrocławiu, 2012,

5. Paszota Z.: Effect of the working liquid compressibility on the picture of volumetric and mechanical losses in a high pressure displacement pump used in a hydrostatic drive. Part II Mechanical losses in a pump //International Scientific-Technical Conference Hydraulics and Pneumatics, Wrocław, 16 - 18 maja 2012 / Ośrodek Doskonalenia Kadr SIMP - Wrocław : ODK SIMP we Wrocławiu, 2012,

6. Paszota Z.: Effect of the working liquid compressibility on the picture of volumetric and mechanical losses in a high pressure displacement pump used in a hydrostatic drive. Part I Energy losses in a drive system, volumetric losses in a pump// Polish Maritime Research 2/2012, Vol. 19
7. Paszota Z.: Effect of the working liquid compressibility on the picture of volumetric and mechanical losses in a high pressure displacement pump used in a hydrostatic drive. Part II Mechanical losses in a pump // Polish Maritime Research 3, 2012, Vol.19

8. Paszota Z.: Theoretical and mathematical models of the torque of mechanical losses in the pump used in a hydrostatic drive (in Polish). Chapter in the monograph: „Research, design, production and operation of hydraulic systems" (in Polish) Adam Klich, Antoni Kozieł and Edward Palczak editors. „Cylinder” Library. „Komag” Mining Mechanisation Centre, Gliwice 2011

9. Paszota Z.: Theoretical and mathematical models of the torque of mechanical losses in the pump used in a hydrostatic drive. (in Polish). „Napędy i sterowanie”, scientific monthly 10/2011

10.Paszota Z.: Theoretical models of the torque of mechanical losses in the pump used in a hydrostatic drive. Polish Maritime Research 4 / 2011, Vol. 18

11.Guillon M.: Theory and calculation of hydraulic systems (in Polish). Wydawnictwa Naukowo-Techniczne Warszawa 1967

12.Osiecki A.: Hydrostatic drive of machine (in Polish). Wydawnictwa Naukowo-Techniczne Warszawa 2004

13.Paszota Z.: $\quad$ Method of determination the degree of liquid aeration in a variable capacity displacement pump. //Polish Maritime Research 3/2013, vol.20

\section{CONTACT WITH THE AUTHOR}

Jan Koralewski, M. Sc.

Faculty of Ocean Engineering and Ship Technology

Gdansk University of Technology Narutowicza 11/12

80-233 Gdansk, POLAND e-mail:.jkoral@pg.gda.pl 